ARTICLE

https://doi.org/10.1038/s41467-019-10319-5

\title{
A bioactive mammalian disaccharide associated with autoimmunity activates STING-TBK1- dependent immune response
}

\author{
Charles S. Fermaintt ${ }^{1}$, Kanae Sano ${ }^{2}$, Zhida Liu ${ }^{3}$, Nozomi Ishii ${ }^{2}$, Junichi Seino ${ }^{4}$, Nicole Dobbs ${ }^{1}$, Tadashi Suzuki ${ }^{4}$,
} Yang-Xin Fu (1) ${ }^{3}$, Mark A. Lehrman ${ }^{5}$, Ichiro Matsuo (D) ${ }^{2}$ \& Nan Yan (1) 1,6

Glycans from microbial pathogens are well known pathogen-associated molecular patterns that are recognized by the host immunity; however, little is known about whether and how mammalian self-glycans activate the host immune response, especially in the context of autoimmune disease. Using biochemical fractionation and two-dimensional HPLC, we identify an abundant and bioactive free glycan, the Man $\beta 1-4 G I c N A c$ disaccharide in TREX1-associated autoimmune diseases. We report that both monosaccharide residues and the $\beta 1-4$ linkage are critical for bioactivity of this disaccharide. We also show that Man $\beta 1-4 G I c N A c$ is produced by oligosaccharyltransferase hydrolysis of lipid-linked oligosaccharides in the ER lumen, followed by ENGase and mannosidase processing in the cytosol and lysosomes. Furthermore, synthetic Manß1-4GIcNAc disaccharide stimulates a broad immune response in vitro, which is in part dependent on the STING-TBK1 pathway, and enhances antibody response in vivo. Together, our data identify Manß1-4GIcNAc as a novel innate immune modulator associated with chronic autoimmune diseases.

\footnotetext{
${ }^{1}$ Department of Immunology, University of Texas Southwestern Medical Center, Dallas, TX 75390, USA. ${ }^{2}$ Division of Molecular Science, Gunma University, Maebashi 371-8510, Japan. ${ }^{3}$ Department of Pathology, University of Texas Southwestern Medical Center, Dallas, TX 75390, USA. ${ }^{4}$ Glycometabolic Biochemistry Laboratory, RIKEN Cluster for Pioneering Research, Wako 351-0198, Japan. ${ }^{5}$ Department of Pharmacology, Department of Microbiology, University of Texas Southwestern Medical Center, Dallas, TX 75390, USA. ${ }^{6}$ Department of Microbiology, University of Texas Southwestern Medical Center, Dallas, TX 75390, USA. Correspondence and requests for materials should be addressed to N.Y. (email: nan.yan@utsouthwestern.edu)
} 
T he seminal work of immunologist Karl Landsteiner around 1900 identifying ABO blood groups led to the discovery that glycans can be powerful immunogens in humans. Later work demonstrated that innate immunity often recognizes glycans on pathogens to prevent infection. The mammalian innate immune system has evolved pattern recognition receptors (PRRs) to recognize microbial components termed pathogenassociated pattern molecules (PAMPs), which range from nucleic acids to lipids, peptides, and glycans ${ }^{1,2}$. This immune surveillance network can also be erroneously activated by self-ligands that mimic microbial PAMPs, thus leading to chronic autoimmune diseases. One such example is $\alpha$-mannosidase-II deficiency, which causes production of hybrid $\mathrm{N}$-glycans that bear immunestimulatory mannose-dependent ligands that promote autoimmune disease in mice similar to lupus ${ }^{3}$.

We recently characterized TREX1, a gene associated with several recessive and dominant autoimmune and autoinflammatory diseases ${ }^{4}$. TREX1 is an ER-anchored DNase with two independent functions, cytosolic DNA clearance function through the $\mathrm{N}$-terminal DNase domain and free glycan anabolism regulation function through the C-terminal ER domain ${ }^{5,6}$. Trex1 ${ }^{-/-}$mice (loss of both DNase and glycan functions) develop severe early-onset systemic autoinflammatory disease with a short lifespan of 2-3 months $s^{5,7}$. In contrast, inactivating either DNase or glycan function alone in mice leads to less severe disease. For example, TREX1-D18N mutant mice disrupting only the DNase activity develop similar but significantly less severe disease phenotypes compared to Trex $1^{-/-}$mice, and these mutant mice also survive much longer ${ }^{8}$. We previously showed that TREX1-V235fs mutant mice express a DNase-active TREX1 truncation that lack glycan regulatory function and develop serologic autoimmunity by producing free glycans and autoantibodies against non-nuclear self-protein antigens $s^{5,6}$.

The glycan regulatory function of TREX1 is associated with its C-terminus. Frame-shift mutations that truncate TREX1 Cterminus are associated with dominant late-onset immune disorders, such as systemic lupus erythematosus (SLE) and retinal vasculopathy with cerebral leukodystrophy (RVCL) ${ }^{9,10}$. We previously demonstrated that loss of TREX1 C-terminus dysregulates the mammalian oligosaccharyltransferase (OST) activity leading to accumulation of free oligosaccharides (fOS) in the cell, and that fOSs activate interferon-stimulated genes (ISGs) in macrophages 5 . However, the identities of the bioactive fOSs and how they are sensed by the immune system remain elusive. Here, we describe a major bioactive mammalian fOS, Man $\beta 1-4 \mathrm{GlcNAc}$, from Trex1-associated autoimmune disease. We also define structural requirements for bioactivity and immune profile of this self-derived disaccharide as well as its biogenesis and immune sensing pathway.

\section{Results}

Identification of a bioactive mammalian disaccharide. We previously showed that fOS pools isolated from Trex1 ${ }^{-/-}$cells are immunogenic when incubated with macrophages ${ }^{5}$. To determine the specific glycan structure(s) that are responsible for immune activation, we performed size exclusion fractionation of the Trex $1^{-/}$fOS pool and examined the bioactivity of each fraction on macrophages. We also analyzed each fraction by fluorophore-assisted carbohydrate electrophoresis (FACE). The majority of the fOS eluted in fractions \#8-11 with larger structures eluting in fraction 8 , medium structures in fraction 9 , and smaller structures in fractions 10 and 11 (Fig. 1a). We then incubated fOS from each fraction as well as the non-fractioned fOS pool with RAW264.7 cells (a mouse macrophage cell line) for $24 \mathrm{~h}$ and measured immune activation. We chose Cxcl10 mRNA expression as our initial 'immune activity' readout because it was the most induced ISG in TREX1-V235fs RVCL patient lymphoblast cells ${ }^{5}$. Fraction 10 stimulated Cxcl10 the strongest; fraction 8 and 11 also appeared to be immunogenic but less potent compared to fraction 10 (Fig. 1a). The pattern of fOS fractionation and immune activity were highly consistent over four experiments. We also compared the immune profile of each fraction that contains fOS $(\# 8-\# 11)$ by stimulating mouse bone marrow derived macrophages (BMDMs) and qRT-PCR array analysis of a panel of immune genes including type I interferon genes (IFN), IFN-stimulated genes (ISGs), inflammatory cytokine, and chemokine genes (Supplementary Fig. 1). We found that each fOS fraction stimulated a distinct immune profile. For example, fraction 10 stimulated the strongest $C x c 110$ expression, whereas fraction 9 stimulated the strongest $I l 10$ expression. Both fraction 10 and 11 stimulated Ifna and Cxcl2 expression to similar levels. These data suggest that multiple bioactive fOS structures exist in the Trex $1^{-/-}$fOS pool.

To gain detailed structural information on these fOSs, we also analyzed WT and Trex $1^{-/}$fOS pool by two-dimensional HPLC analysis (i.e., size-fractionation HPLC followed by dual-gradient reversed-phase $\mathrm{HPLC}^{11}$ ). The most enriched fOS structures in Trex $1^{-1-}$ MEFs are paucimannose structures with one reducingterminal GlcNAc $\left(\operatorname{Man}_{1-3} \mathrm{GlcNAc}\right)$ at $\sim 20$ fold higher levels than WT (Fig. 1b, Supplementary Fig. 2). Interestingly, the top three enriched glycan species match well with the predicted size of fOSs observed in fraction 10. We thus compared fraction 10 with chemically synthesized disaccharide (Man $\beta 1-4 \mathrm{GlcNAc}$, in-house, see Supplementary Methods), trisaccharide $\left(\mathrm{Man}_{2} \mathrm{GlcNAc}\right.$, inhouse, see Supplementary Methods), and larger high-mannose glycans ( $\mathrm{Man}_{5} \mathrm{GlcNAc}_{2}$ and $\mathrm{Man}_{9} \mathrm{GlcNAc}_{2}$, purchased from Sigma) by FACE. We found that the two major fOS species in fraction 10 co-migrate with the disaccharide (ManGlcNAc) and trisaccharide $\left(\mathrm{Man}_{2} \mathrm{GlcNAc}\right)$ standards (Fig. 1c). No other fractions contain detectable amount of disaccharide (ManGlcNAc) structure by FACE (Fig. 1c). Thus, we chose fraction 10 and the two fOS structures it contains for further analysis based on their high abundance and unique immune profile.

To see if any of these two fOS structures are bioactive, we stimulated RAW264.7 cells with increasing concentrations of the synthetic $\mathrm{Man}_{2}$ GlcNAc and ManGlcNAc and measured Cxcl10 mRNA expression. Only ManGlcNAc induced Cxcl10 expression in a dose-dependent manner, while $\mathrm{Man}_{2} \mathrm{Gl}_{\mathrm{cNAc}}$ lacked bioactivity in this assay (Fig. 1d). Together, these experiments suggest that the ManGlcNAc disaccharide is a bioactive glycan that is highly enriched in the Trex $1^{-/-}$fOS pool.

Bioactivity is specific to only the Man $\beta 1-4 G l c N A c$ disaccharide. In our HPLC experiments we also analyzed Trex1 ${ }^{-1-}$ fOS pool after digestion with $\alpha$-mannosidases, and we found that the ManGlcNAc disaccharide peak was not affected by digestion, suggesting that the glycosidic bond is a $\beta$ linkage (Fig. 1b). To determine if the $\beta$ linkage is critical for the bioactivity of the ManGlcNAc disaccharide, we treated cellular Trex $1^{-/-}$fOS pool and the synthetic ManGlcNAc disaccharide with $\alpha$ - or $\beta$ mannosidase that selectively cleaves $\alpha$ - or $\beta$-mannosylated linkages, respectively, and assayed the digested glycan structures by FACE and bioactivity by stimulating macrophages and measuring Cxcl10 expression. a-Mannosidase treatment removed most of the high molecular weight fOSs from the Trex1 $1^{-1-}$ fOS pool but had no effect on the disaccharide band in the cellular fOS pool or synthetic ManGlcNAc disaccharide (Fig. 1e). In contrast, $\beta$ mannosidase digested the synthetic ManGlcNAc disaccharide as well as the disaccharide band in the fOS pool (Fig. 1e). $\beta$ mannosidase treatment reduced bioactivity of the fOS pool and 
a
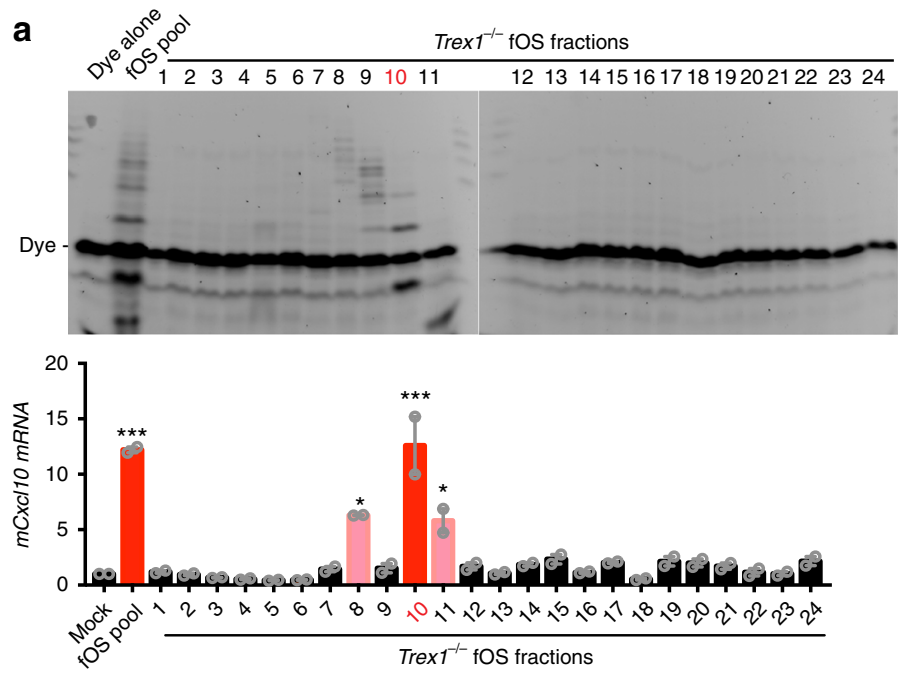

c
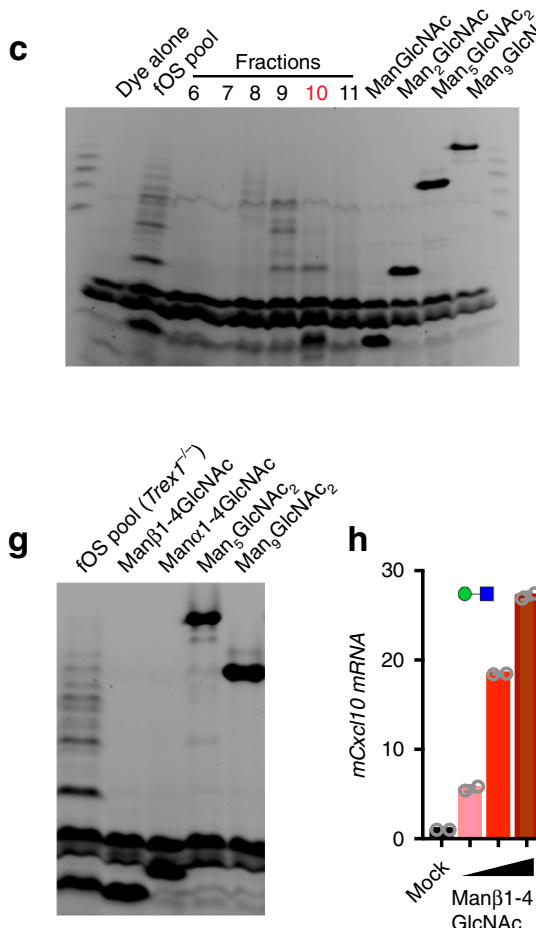

$\mathrm{h}$
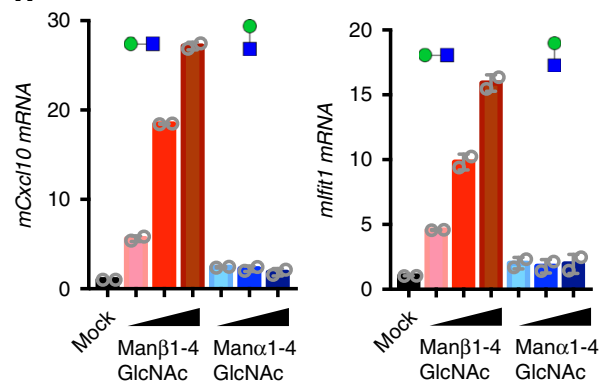

b

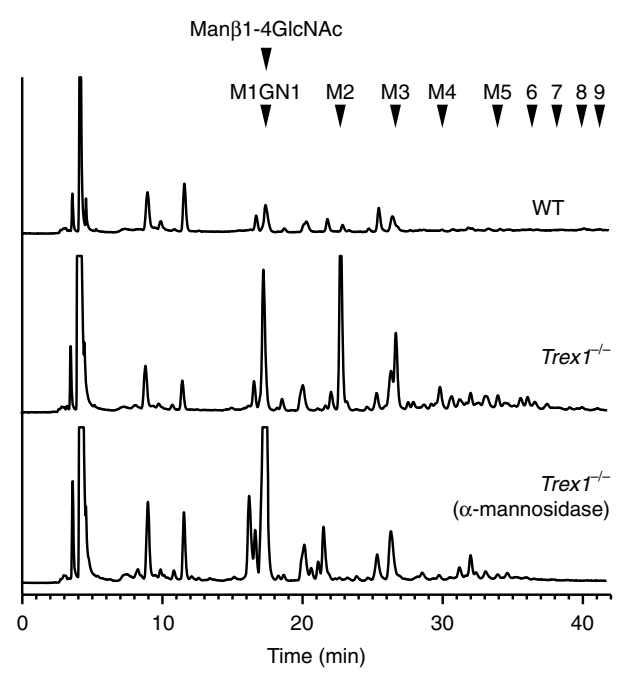

e

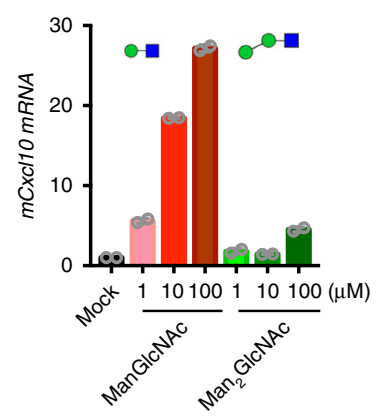

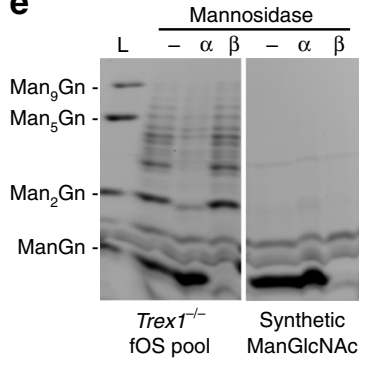

f

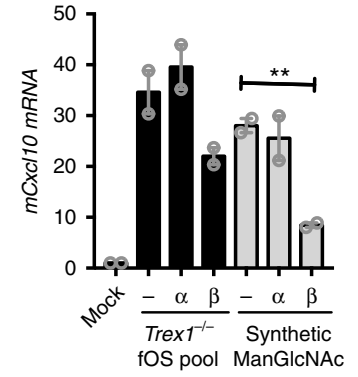

i
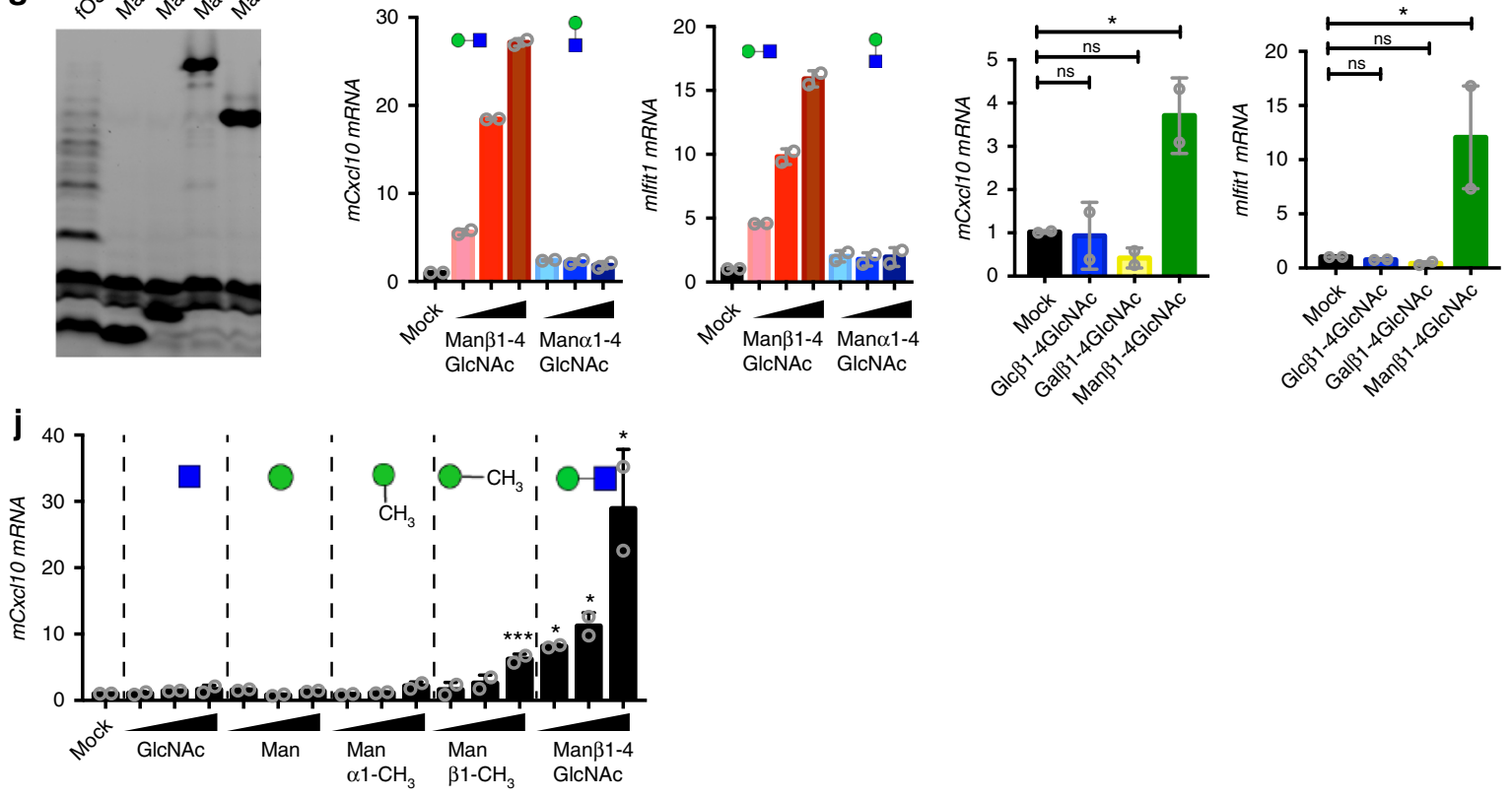

bioactivity of the synthetic ManGlcNAc disaccharide, whereas $\alpha$ mannosidase treatment had no effect (Fig. 1f). The residual activity in $\beta$-mannosidase-treated fOS pool indicates that other immunogenic fOS species also present in the fOS pool, consistent with our earlier observation that bioactivies were detected in multiple fractions from the fOS pool.
Glycosidic bonds can exist in two anomeric configurations, a or $\beta$. We next synthesized Mana1-4GlcNAc and compared its bioactivity to Man $\beta 1-4 \mathrm{GlcNAc}$ (see Supplementary Methods). FACE analysis (which separates glycan based upon both oligosaccharide length and tertiary structural features that distinguish anomers and epimers) showed co-migration of 
Fig. 1 Identification of a bioactive mammalian disaccharide Man $\beta 1-4 G I c N A c$. a Size exclusion fractionation of Trex $1^{-/-}$MEFs fOS pool and bioactivity of each fraction. Top panel, FACE analysis of each fraction. Bottom panel, quantitative RT-PCR analysis of mCxcl10 mRNA in RAW264.7 cells (permeabilized by digitonin, same below) stimulated for $24 \mathrm{~h}$ with each fraction. b Two-dimensional HPLC analysis of fOS enriched in wild-type (WT), Trex $7^{-/-}$MEFs and Trex $1^{-/}-$fOS treated with $\alpha$-mannosidases (see Methods). Quantitation and structure of top five enriched fOSs, identified by the second reverse-phase

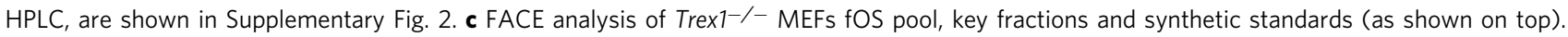
d Quantitative RT-PCR analysis of $m C x c 110$ mRNA in RAW264.7 cells that were stimulated with increasing amounts $(1,10$, and 100 $\mu$ M) of the synthetic $\mathrm{Man}_{2} \mathrm{GlCNAc}_{1}$ and ManGlcNAc${ }_{1}$. e, f FACE analysis (e) and bioactivity (f) of untreated or $\alpha$ - or $\beta$-mannosidase digested Trex $1^{-/-}$MEFs fOS pool or the synthetic ManGlcNAc disaccharide. Bioactivity of each fOS sample was measured by quantitative RT-PCR analysis of $m C x c / 10$ mRNA in RAW264.7 cells stimulated for $24 \mathrm{~h}$ with indicated fOS samples. (g) FACE analysis of Trex1-/- MEFs fOS pool, and synthetic Man $\beta 1-4 G l c N A c$, Man 1 1-4GlcNAc, $\mathrm{Man}_{9} \mathrm{GlcNAc}_{2}, \mathrm{Man}_{5} \mathrm{GlcNAc}_{2} . \mathbf{h}$ Quantitative RT-PCR analysis of $m \mathrm{Cxcl10}$ and mlfit1 mRNA in RAW264.7 cells that were stimulated with increasing amounts $(1,10$, and $100 \mu \mathrm{M})$ of the synthetic Man $\beta 1-4 \mathrm{GlcNAc}$ and Man $\alpha 1-4 \mathrm{GlcNAc}$ for $24 \mathrm{~h}$. i Quantitative RT-PCR analysis of $m C x c / 10$ and $m / f i t 1 \mathrm{mRNA}$ in RAW264.7 cells that were stimulated with $10 \mu \mathrm{M}$ of Glc $\beta 1-4 \mathrm{GlcNAc}$, Gal $\beta 1-4 \mathrm{GlcNAc}$, and Man $\beta 1-4 \mathrm{GlcNAc}$. j Quantitative RT-PCR analysis of $m C x c / 10$ mRNA in RAW264. 7 cells that were stimulated with increasing amounts $(10,100$, and $1000 \mu \mathrm{M})$ of Mannose, GlcNAc, Man $\alpha 1-\mathrm{CH}_{3}, \mathrm{Man}_{3} 1-\mathrm{CH}_{3}$, and Man $\beta 1-4 G I c N A c$. Data are representative of at least three independent experiments. Error bars indicate SEM. Unpaired $t$-test. ${ }^{\star} P<0.05,{ }^{\star \star} P<0.01,{ }^{\star \star \star} P<$ $0.001,{ }^{\star \star \star \star} P<0.0001$, ns not significant (same throughout)

Man $31-4$ GlcNAc but not Mana1-4GlcNAc with the disaccharide band in the Trex $1^{-/-}$fOS pool (Fig. 1g). Remarkably, only Manß1-4GlcNAc, but not Mana1-4GlcNAc, stimulated Cxcl10 and Ifit1 expression in RAW267.4 cells, suggesting that the bioactivity was associated with the $\beta 1-4$ linkage (Fig. 1 h). We next compared Man $\beta 1-4$ GlcNAc to other disaccharides that also contain the $\beta 1-4$ linkage, such as Glc $\beta 1-4 G l c N A c$ and Gal $\beta 1$ 4GlcNAc (see Supplementary Methods). Again, only Man $\beta 1$ 4GlcNAc disaccharide was immunogenic (Fig. 1i). We also examined the bioactivity of monosaccharides such as Man, GlcNAc, $\alpha$-methyl mannose (Mana1- $\mathrm{CH}_{3}$ ), and $\beta$-methyl mannose $\left(\mathrm{Man} \beta 1-\mathrm{CH}_{3}\right)$. None of the monosaccharides were able to stimulate Cxcl10 expression to the extent of the Man $\beta 1-4 \mathrm{GlcNAc}$ disaccharide in macrophages (Fig. 1j). $\mathrm{Man} \beta 1-\mathrm{CH}_{3}$ had some activity but required 100 times higher concentration than $\operatorname{Man} \beta 1$ 4 GlcNAc. We also analyzed fOS and immune profile of TREX1$V 235 f s$ mutant mouse BMDMs, and we found increased expression of Cxcl10 and several other immune genes as well as significantly elevated levels of Man $\beta 1-4 \mathrm{GlcNAc}$ disaccharide (Supplementary Fig. 3A, 3B). Together, these results identify Man $\beta 1-4$ GlcNAc as an abundant and bioactive mammalian selfglycan in TREX1-associated autoimmune disease cells. Both the Man and the GlcNAc, as well as the $\beta 1-4$ linkage, are important for full bioactivity of this disaccharide at micromolar concentrations.

Biogenesis and cellular distribution of Man $\beta 1-4 G l c N A c$. Oligomannose fOS can be generated from deglycosylation of ERassociated degradation (ERAD) substrates by $\mathrm{N}$-glycanase NGLY1 or from the hydrolysis of lipid-linked oligosaccharide (LLOs) by the oligosaccharyltransferase $(\mathrm{OST})^{12,13}$. We previously showed that absence of TREX1 or its C-terminus (e.g., TREX1-V235fs mutant) dysregulates the OST activity leading to accumulation of intracellular fOS $^{5}$. To determine the source that leads to production of the Man $\beta 1-4 \mathrm{GlcNAc}$ disaccharide, we used specific inhibitors that block either ERAD or OST activity and measured their effect on fOS production in Trex1-/- MEFs by FACE (Fig. 2a diagram). Inhibiting OST activity with aclacinomycin A $\left(\mathrm{ACM}^{5,14}\right)$ led to significant reduction of $\mathrm{Man} \beta 1$ 4GlcNAc disaccharide as well as other high-mannose fOSs (Fig. 2b). In contrast, inhibiting of NGLY1 with Z-VAD-fmk ${ }^{15}$ had no effect on the Man $\beta 1-4 G l c N A c$ disaccharide or any other fOSs (Fig. 2c). We next examined ER translocation and glycan processing machinery in the lumen. Inhibiting ER glucosidases with castanospermine (CSN) blocks both the translocation of fOS to the cytoplasm as well as the progress through ERAD ${ }^{16,17}$, while inhibition of ER lumenal mannosidases with kifunensine (KIF) only affects misfolded protein tagging for ERAD ${ }^{18,19}$. Trex1 $1^{-/-}$
MEFs treated with CSN significantly reduced Man $\beta 1-4$ GlcNAc disaccharide while treatment with KIF had no impact, suggesting that fOS derived from LLO hydrolysis are exported to the cytosol as large structures before trimming by ER luminal mannosidases (Fig. 2d, e and Supplementary Fig. 4A, 4B). We also tested cycloheximide (CHX, inhibits protein synthesis), MG132 (inhibits proteasomal degradation), and eeyarestatin I (ES1, inhibits ERAD), and none had any effect on the Man $\beta 1-4 \mathrm{GlcNAc}$ disaccharide level in Trex $1^{-/}-$MEFs (Supplementary Fig. 4C-4K). These data suggest that OST-hydrolyzed LLOs are precursors of the Man $31-4$ GlcNAc disaccharide.

We next investigated how fOSs generated from LLOs get further processed into the Man $\beta 1-4$ GlcNAc disaccharide. fOS derived from $\mathrm{N}$-glycosylated proteins are processed by endo- $\beta-\mathrm{N}$ acetylglucosaminidase (ENGase) in the cytosol. We thus examined the role of the ENGase pathway, which includes first trimming fOSs to $\mathrm{Man}_{5} \mathrm{GlcNAc}$, transfer into the lysosomes and then further processed by $\alpha$ - and $\beta$-mannosidases into Man $\beta 1$ $4 \mathrm{GlcNAc}$ disaccharide and monosaccharides ${ }^{20-22}$ (Fig. 3a diagram). ENGase knockdown by siRNA in Trex1-/- MEFs led to reduced Man $\beta 1-4 G l c N A c$ disaccharide levels as well as a corresponding increase in high molecular weight fOSs that comigrated with previously characterized species in Engase ${ }^{-1-}$ $\mathrm{MEFs}^{23}$ (Fig. 3b and Supplementary Fig. 5A). Conversely, MANBA (encodes $\beta$-mannosidase) knockdown led to increased Man $\beta 1-4$ GlcNAc disaccharide level, further confirming the $\beta$ linkage in the disaccharide and suggesting that $\beta$-mannosidase is the critical last enzyme in the pathway that breaks down the disaccharide (Fig. 3c and Supplementary Fig. 5B). Chloroquine treatment (CQ, lysosome neutralizer, thus inactivates $\beta$ mannosidase in the lysosome) also increased the disaccharide (Supplementary Fig. 5C, 5D). Because mammalian cells have multiple genes encoding a-mannosidase, we next treated Trex $1^{-/-}$MEFs with a broad $\alpha$-mannosidase inhibitor swainsonine $\left(S_{w a i n}{ }^{24}\right)$. Swainsonine completely eliminated the Man $\beta 1$ 4GlcNAc disaccharide from Trex $1^{-/-}$fOS and accumulated the $\mathrm{Man}_{3-5}$ GlcNAc intermediates (Fig. 3d). We previously showed that ACM treatment inhibits OST activity and reduces ISG expression in Trex $1^{-/-}$cells $^{5}$. We next treated WT and Trex1 $1^{-/-}$ MEFs with increasing dose of swainsonine, and we observed dose-dependent decrease of ISG expression (Fig. 3e, 3f). These data suggest that LLO-derived fOSs move from the ER lumen to the cytosol followed by processing by ENGase and $\alpha$ mannosidases to produce the Man $\beta 1-4$ GlcNAc disaccharide. Also, interruption of Man $\beta 1-4$ GlcNAc biogenesis in Trex1-/cells reduces immune activation.

We next wanted to examine the cellular distribution of the mammalian Man $\beta 1-4 \mathrm{GlcNAc}$ disaccharide. Treating the 

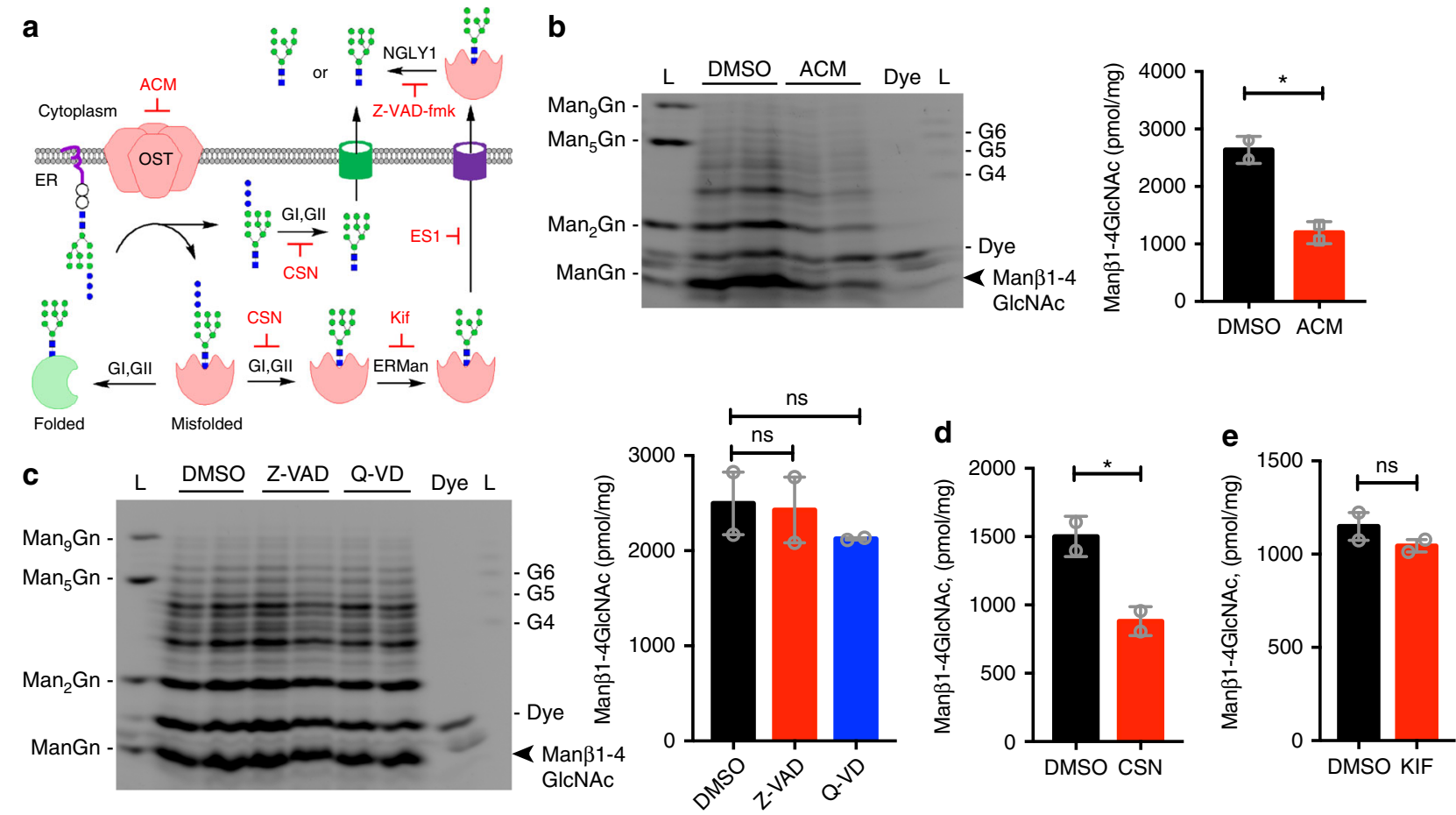

Fig. 2 The Man $\beta 1-4 G I c N A c$ disaccharide originates from glycans produced by the OST. a A schematic diagram of two major biogenesis pathways of fOS in mammalian cells, OST hydrolysis of LLO and NGLY1 cleavage of N-glycans, and pharmacological inhibitors (red) that blocks either pathway. b FACE analysis of fOS pool isolated form Trex $1^{-/-}$MEFs treated with $1 \mu \mathrm{M}$ aclacinomycin (ACM) for $24 \mathrm{~h}$. Quantification of the Man $\beta 1-4 \mathrm{GlcNAc}$ disaccharide band is shown on the right (same below). c FACE analysis of fOS pool isolated form Trex 1-/- MEFs treated with $30 \mu \mathrm{M} Z$ Z-VAD or $50 \mu \mathrm{M}$ Q-VD for $24 \mathrm{~h}$. d, e Quantification of the Man $\beta 1-4$ GIcNAc disaccharide in Trex1-/- MEFs treated with $100 \mu \mathrm{M}$ of castanospermine (CSN, D) or $100 \mu \mathrm{M}$ of kifunensine (KIF, E) for $24 \mathrm{~h}$. Representative FACE gels are in Supplementary Fig. 4. Data are representative of at least three independent experiments. Error bars indicate SEM. Unpaired t-test

Trex $1^{-/-}$MEFs with digitonin $(10 \mu \mathrm{g} / \mathrm{mL})$ that only permeabilized the plasma membrane ${ }^{25}$ led to lost of nearly half of the disaccharide, suggesting that a substantial fraction of Man $\beta 1$ $4 \mathrm{GlcNAc}$ resides in the cytosol (Supplementary Fig. 5E). We also compared fOSs isolated from media and from cell lysates originated from the same tissue culture dish with a monolayer of healthy cells, and we found similar amount of the Man $\beta 1$ 4GlcNAc disaccharide in both intracellular and extracellular compartments (Supplementary Fig. 5F). Together, these findings demonstrate that the bioactive Man $\beta 1-4 \mathrm{GlcNAc}$ disaccharide resides in both intracellular and extracellular space.

Manß1-4GlcNAc activates immune signaling via TBK1 and NF-kB. We performed RNA-seq to investigate the immune response activated by the synthetic Man $\beta 1-4$ GlcNAc disaccharide or cellular Trex1-I- fOS pool in RAW267.4 macrophages. We found that 2044 genes were differentially expressed after the Man $31-4 \mathrm{GlcNAc}$ disaccharide stimulation, 1131 genes after fOS pool stimulation, and 760 genes are shared between the two (Supplementary Fig. 6A). Ingenuity pathways analysis on the 760 shared genes revealed top pathways involved in T helper cell differentiation, antigen presentation, and upregulation of various chemokine genes from the CXCL family (Supplementary Fig. 6B). We validated several groups of immune genes including IFN, ISGs, inflammatory genes, and chemokine genes by qRT-PCR. The Man $\beta 1-4 G l c N A c$ disaccharide and fOS pool stimulated broad expression of immune genes including IFN and ISGs (as we observed before ${ }^{5}$ ) and many CXCL and CCL family chemokine genes (Fig. 4a).

To investigate whether Man $\beta 1-4 \mathrm{GlcNAc}$ is detected by intracellular or extracellular receptors, we prepared permeabilized and non-permeabilized RAW267.4 cells and BMDMs and incubated them with Man $\beta 1-4 \mathrm{GlcNAc}$ disaccharide. Primary macrophages such as BMDMs are more efficient at phagocytosis than macrophage cell lines such as RAW267.4 cells ${ }^{26}$. We found that Man $\beta 1-4$ GlcNAc disaccharide only stimulated immune gene expression (e.g., Cxcl10, Ifit1) in permeabilized RAW267.4 cells and not in non-permeabilized RAW267.4 cells (Fig. 4b). In contrast, both permeabilized and non-permeabilized BMDMs showed dose-dependent and significant increase of immune gene expression after incubation with Man $\beta 1-4 \mathrm{GlcNAc}$ disaccharide in the media, with permeabilizated BMDMs showing more robust response (Fig. 4c). Man $\beta 1-4$ GlcNAc also induced increased cytokine and chemokine secretion in the media in permeabilized cells (Fig. 4d). Manß1-4GlcNAc did not induce IL-10 expression in any of the conditions (Fig. $4 \mathrm{~b}, \mathrm{c}$ ). These data suggest the possibility of an intracellular sensing pathway for Man $\beta 1$ 4GlcNAc in macrophages.

We next sought to determine which immune pathway is required for sensing the Man $\beta 1-4 \mathrm{GlcNAc}$ disaccharide. We chose a panel of knockout mice that are deficient in genes required for key innate immune signaling pathways (see Supplementary Fig. 6C for a diagram). TBK1 is a protein kinase required by several intracellular innate immune signaling pathways. IFN receptor 1 (IFNAR1) is required for type I IFN response. IRF3 and IRF7 are key transcription factors for IFN and ISG mRNA expression. MYD88 and TRIF are the two essential adaptor proteins required for TLR signaling. MAVS and STING are key non-redundant adaptor proteins for cytosolic RNA and DNA sensing pathways, respectively. We compared the response to the Man $\beta 1-4 G l c N A c$ disaccharide on BMDMs from wild-type,

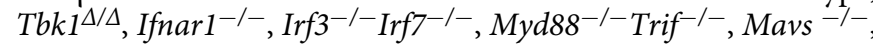


a

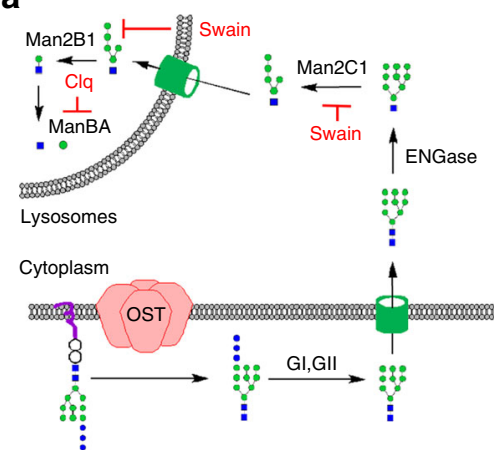

C

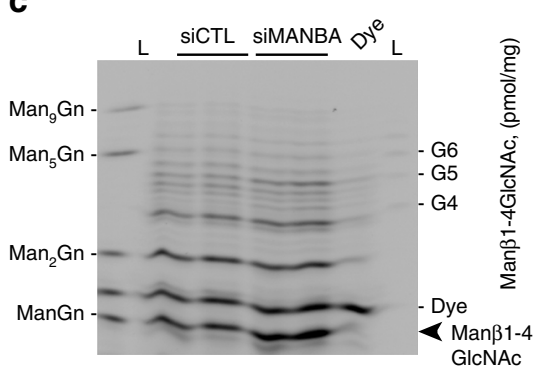

e

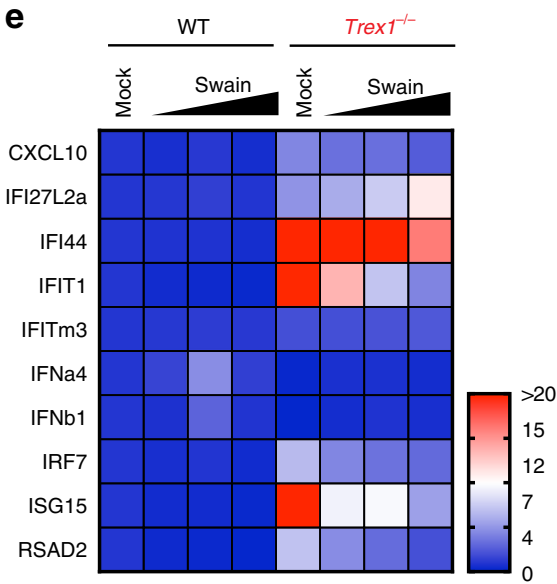

b

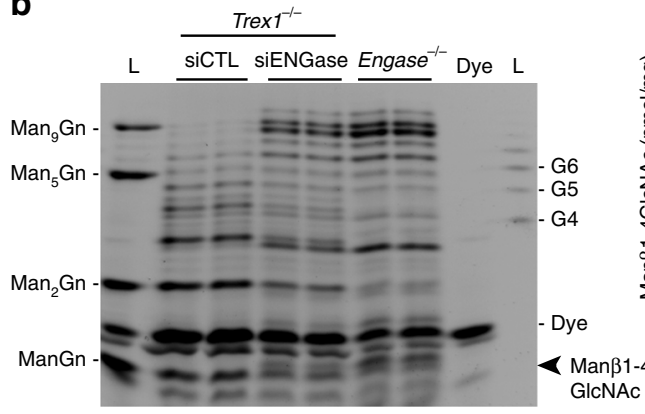

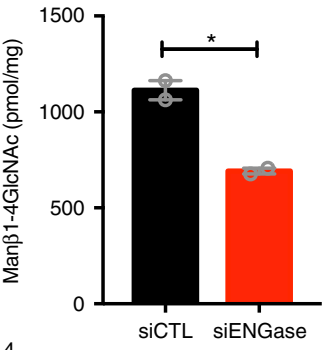

d
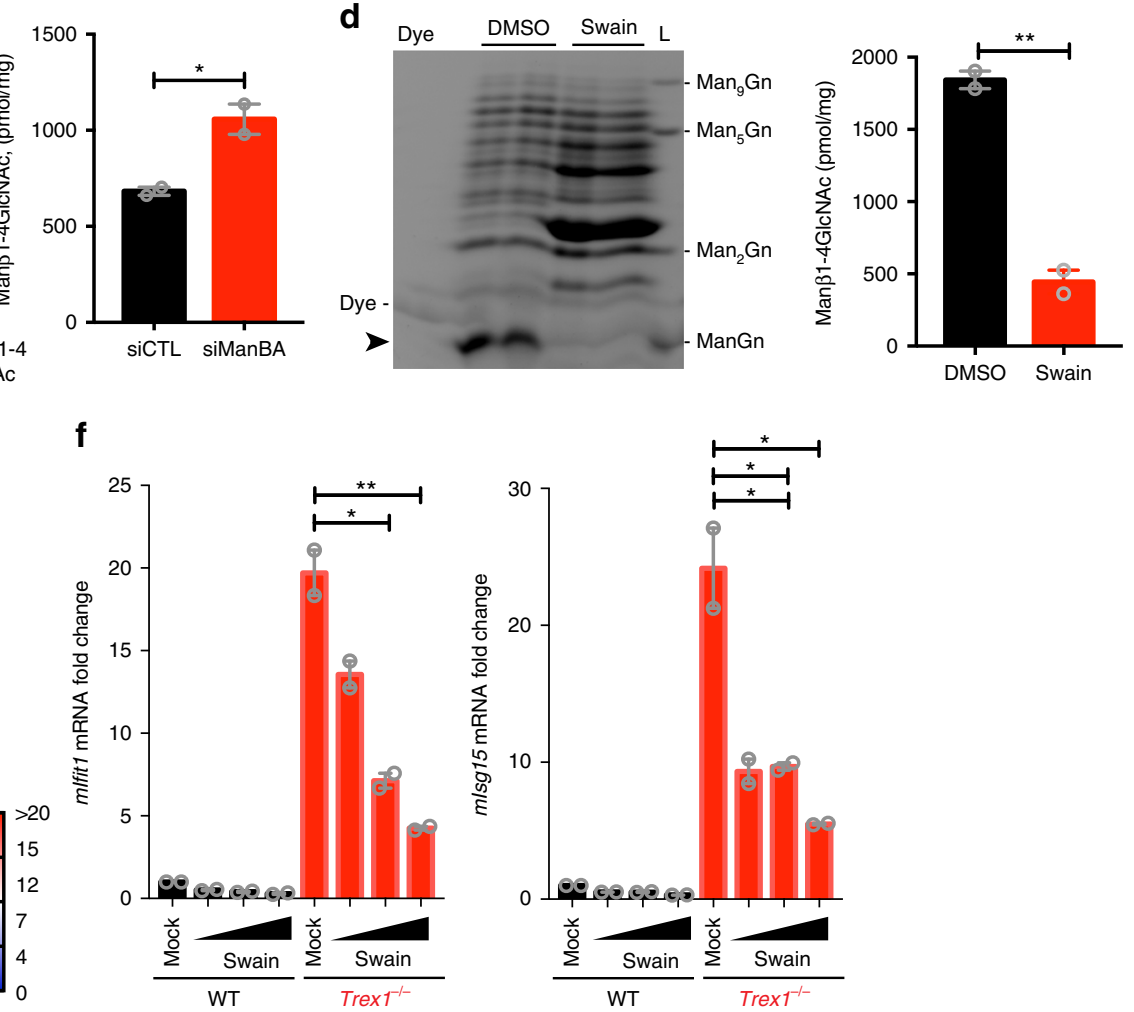

Fig. 3 The Man $\beta 1-4 G I c N A c$ disaccharide biogenesis requires processing by ENGase and $\alpha$-mannosidase. a A schematic diagram of the catabolic processing of luminal fOS and pharmacological inhibitors (red) that blocks each step. b FACE analysis of fOS pool isolated from Trex $1^{-/-}$MEFs treated with si-control or si-ENGase for $48 \mathrm{~h}$ or fOS pool isolated from untreated Engase $\mathrm{I}^{-/-}$MEFs. Quantification of the Man $31-4 \mathrm{GlcNAc}$ disaccharide is shown on the right (same below). c FACE analysis of fOS pool isolated from Trex1 ${ }^{-1}-$ MEFs treated with si-control or si-ENGase for $48 \mathrm{~h}$. Similar to B. d FACE analysis of fOS pool isolated from Trex $1^{-/-}$MEFs treated with $10 \mu \mathrm{M}$ Swain for $24 \mathrm{~h}$. e, $\mathbf{f}$ Quantitative RT-PCR array analysis of immune gene expression in WT and Trex $1^{-/-}$E15.5 primary MEFs treated with mock or Swain $(0.1,1$, and $10 \mu \mathrm{M})$ for $24 \mathrm{~h}$. A heat map summarizing multiple immune genes is shown in e and two representative ISGs are shown in $\mathbf{f}$. Data are representative of at least three independent experiments. Error bars indicate SEM. Unpaired $t$-test

and Sting $-1-$ mice. We found that wild-type, Ifnar $1^{-/-}$, Myd88 ${ }^{-/-}$Trif $^{-/-}$and Mavs-/- BMDMs responded to the Man $\beta 1-4 G l c N A c$ disaccharide stimulation to similar levels. In contrast, $T b k 1^{\Delta / \Delta}$ BMDMs completely ablated immune response to Man $\beta 1-4 \mathrm{GlcNAc}$ while Sting ${ }^{-/-}$and $\operatorname{Irf3} 3^{-/} \operatorname{Irf7^{-/-}}$ partially suppressed immune activation (Fig. 5a). To corroborate and extend on these findings, we pretreated wild-type BMDMs with TBK1 inhibitors (BX795 and Compound II), NF- $\kappa$ B inhibitors (TPCA-1 and dexamethasone), and JAK1/2 inhibitor ruxolitinib (inhibits type I IFN signaling), then stimulated with the Man $\beta 1$ 4 GlcNAc disaccharide. TBK1 and NF- $\kappa$ B inhibitors suppressed the activation of $\mathrm{Cxcl} 10$ and $\mathrm{Cxcl} 2$ while ruxolitinib had no effect (Fig. 5b). Taken together, these studies suggest that Man $\beta 1$ 4 GlcNAc-activated immune response is TBK1- and NF-kBdependent but IFN- and TLR-independent.
Immune gene profile activated by Man $\beta 1-4 G l c N A c$. Myeloid cells, which include macrophages, express an arsenal of carbohydrate binding proteins known as C-type lectins receptors (CLR) that function like PRRs and recognize a wide variety of glycan PAMPs. There are hundreds of lectins that can be potential candidate receptors for Man $\beta 1-4 \mathrm{GlcNAc}$ disaccharide, making the individual knockdown approach impractical. It is also possible that Man $\beta 1-4 G l c N A c$ disaccharide represents a distinct type of bioactivity with its unique monovalent structure and micromolar activity concentration. Thus, we examined whether the Man $\beta 1-4 G l c N A c$ disaccharide stimulates an immune profile that can be matched to other non-mammalian bioactive glycans or non-glycan agonists. We stimulated BMDMs with Dectin-1 ligands (Chitosan, Chitin, Curdlan, and Zymosan), MGL ligand $(\text { Lewis-X })^{6}$, Dectin-2 ligands ( $\beta$-Mannan, $\alpha$-Mannan, Furfurman, 
a

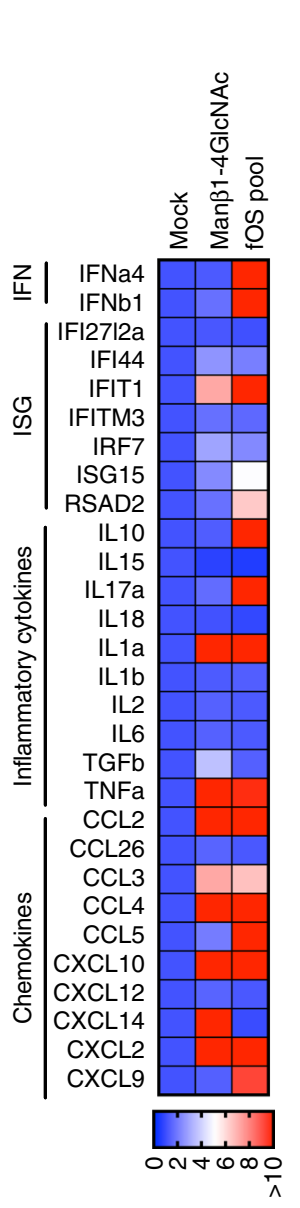

b
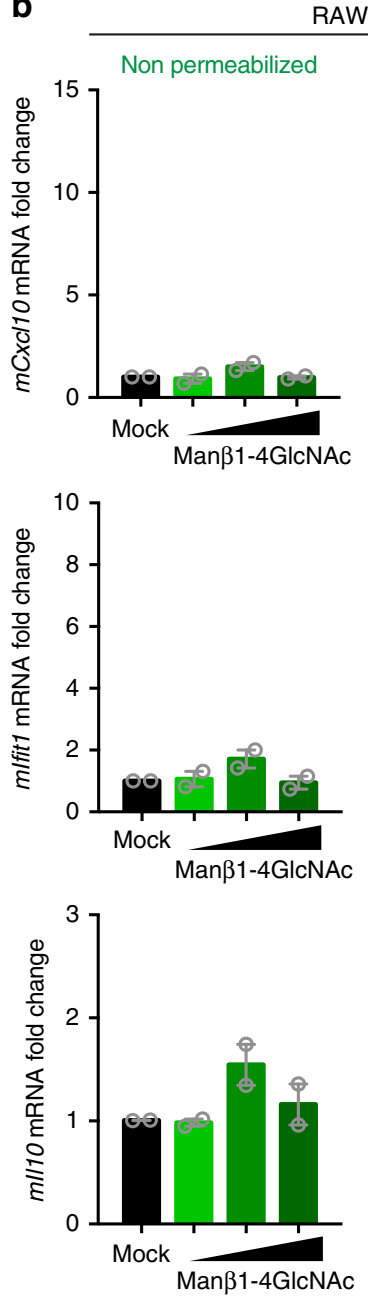

RAW
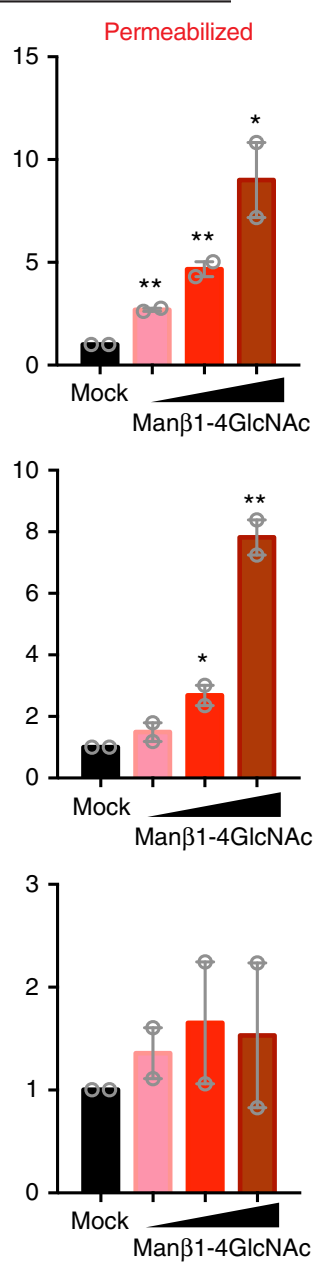

C
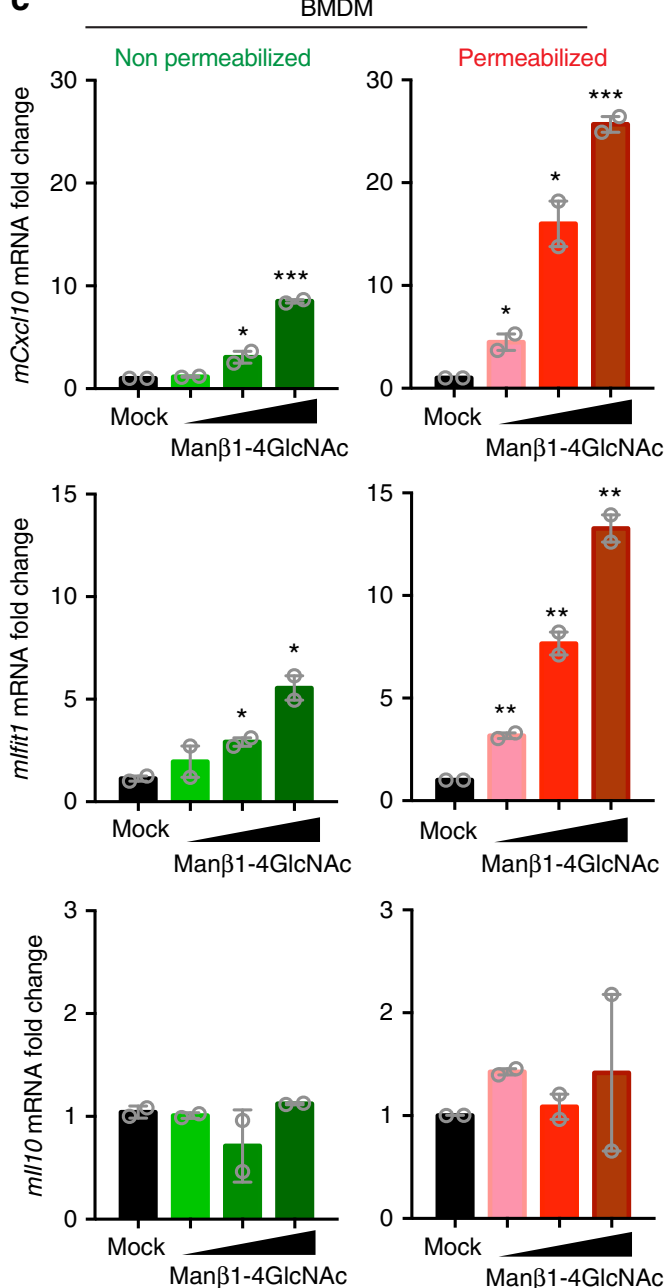
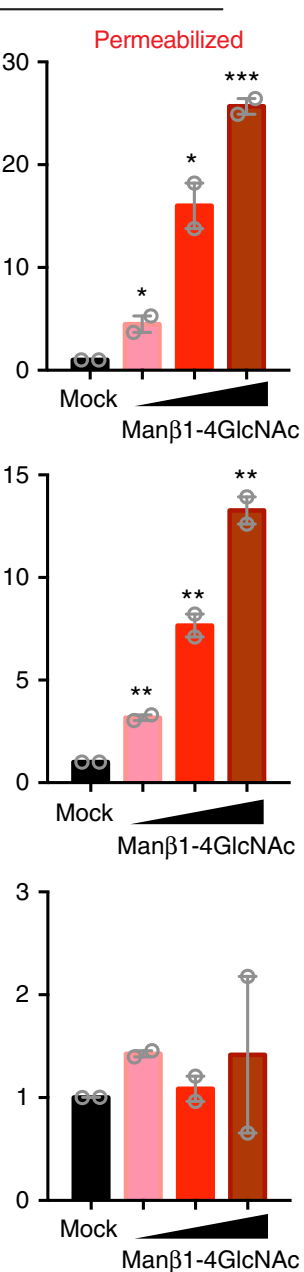

d RAW, permeabilized

BMDM, permeabilized
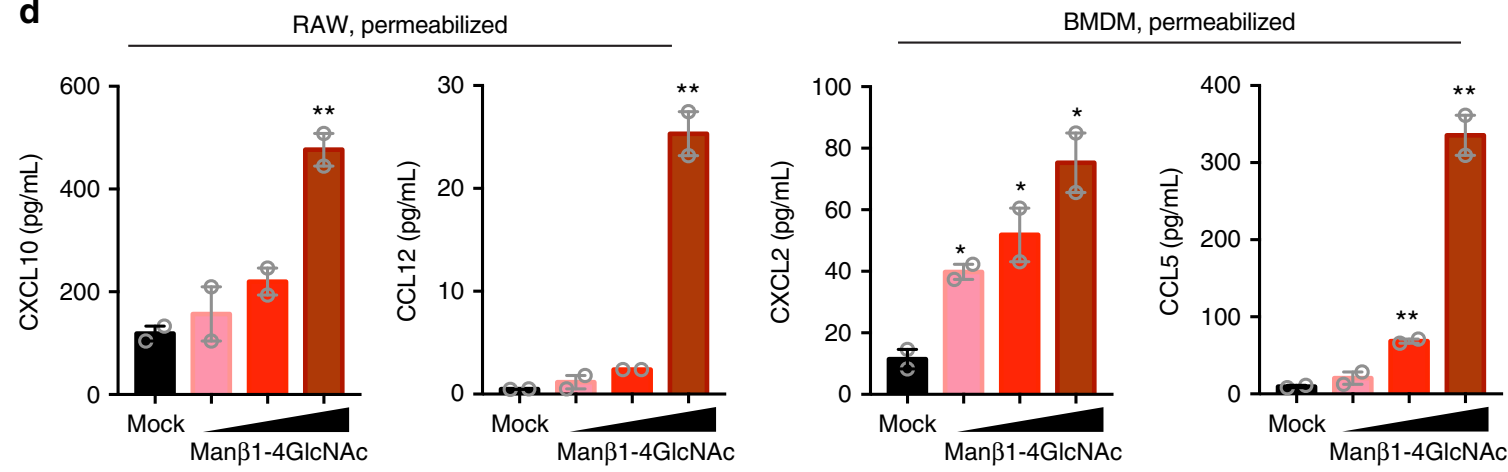

Fig. 4 The Man $\beta 1-4 G I c N A c$ disaccharide activates an intracellular pathway. a A heat map showing immune gene expression profiles induced by Trex $7^{-/-}$ fOS pool or the Man $\beta 1-4 G I c N A c$ disaccharide. Permeabilized RAW264.7 cells were stimulated with $10 \mu \mathrm{M}$ of the Trex1-/- fOS pool or the synthetic Man $\beta 1-$ 4GIcNAc disaccharide followed by quantitative RT-PCR analysis of each indicated mRNA. b, c Quantitative RT-PCR analysis of $m C x c / 10, m / f i t 1$ and $m / 110$ mRNA in RAW264.7 cells (b) or BMDMs (c) that were either non-permeabilized or permeabilized by digitonin (as indicated on top), then cells were treated with mock or increasing amounts $(1,10$ and $100 \mu \mathrm{M})$ of the Man $\beta 1-4 \mathrm{GICNAc}$ disaccharide for $24 \mathrm{~h}$. $\mathbf{d}$ Multiplex ELISA analysis of cytokines and chemokines from experiments in $\mathbf{b}$ and $\mathbf{c}$. Data are representative of at least two independent experiments. Error bars indicate SEM. Unpaired t-test

and Lipoarabinomannan), and MCL/MINCLE ligand (Cord factor) as well as HT-DNA (herring testis DNA, activates cytosolic cGAS-STING-TBK innate immune pathway), LPS (activates TLR4 pathway), Man $\beta 1-4 G l c N A c$ disaccharide, and fOS pool. We then measured the expression of IFN, ISGs, inflammatory, and chemokine genes by qRT-PCR array. After hierarchical clustering that would group ligands with similar immune profiles, Man $31-4$ GlcNAc disaccharide and the fOS pool emerged most similar to HT-DNA and chitosan (Figs. 6a, b). Both HT-DNA and chitosan activate the STING-TBK1 pathway in the cytosol ${ }^{27}$. We next analyzed the STING-TBK1 pathway in more detail by comparing a broader panel of immune genes activated by Man $\beta 1$ 4GlcNAc disaccharide in WT, Tbk $1^{\Delta / \Delta}$, and Sting ${ }^{-/-}$BMDMs. $T b k 1^{\Delta / \Delta}$ ablated all examined immune gene activation by Man $\beta 1$ 4GlcNAc. Interestingly, Sting ${ }^{-1-}$ eliminated expression of ISGs (e.g., Ifi44, Ifit1, Isg15, etc) but had little effect on chemokine 
a

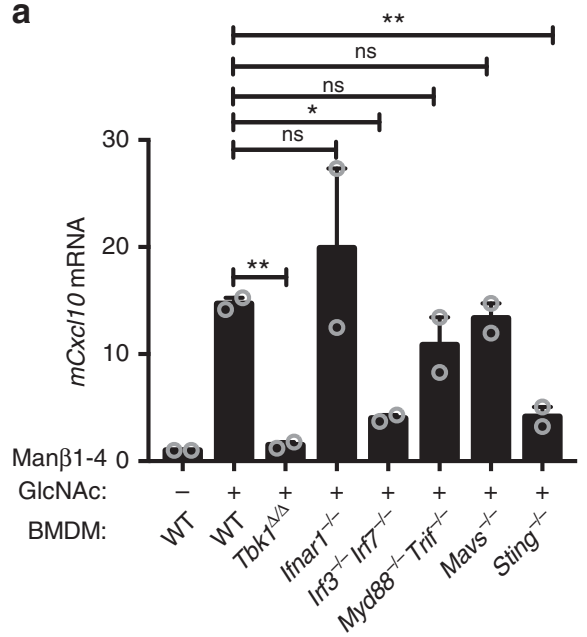

b

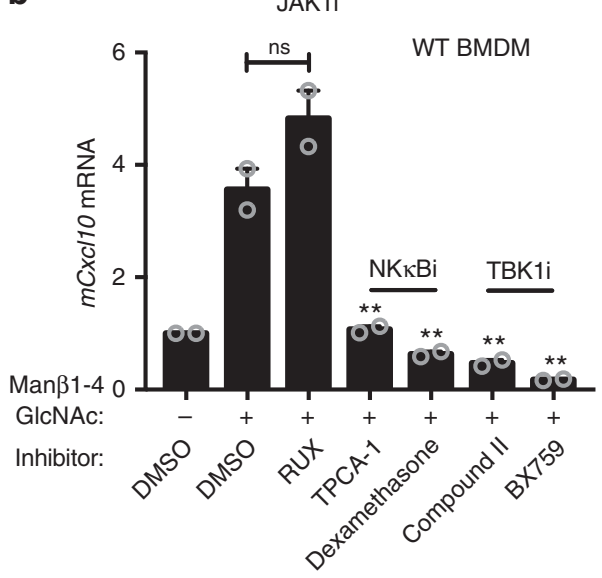

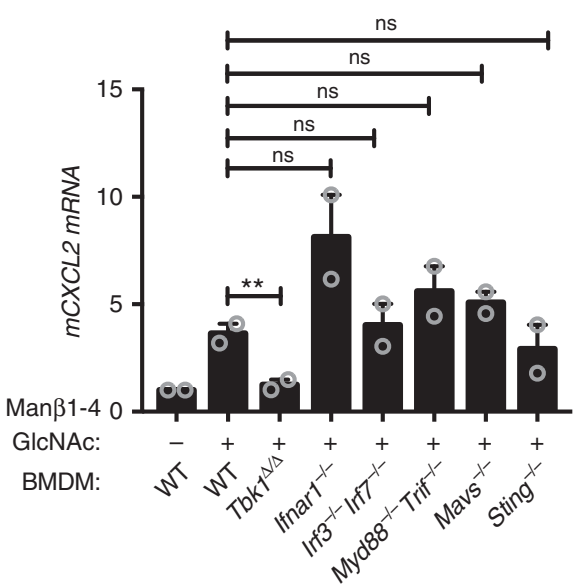

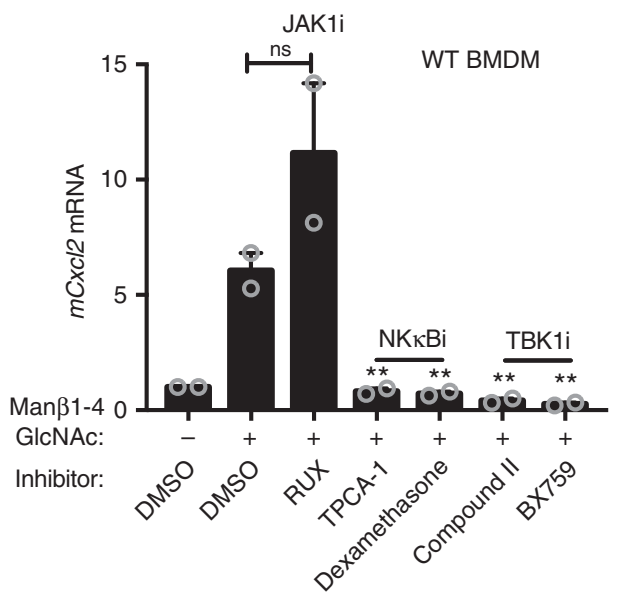

Fig. 5 The Man $\beta 1-4 G I c N A c$ disaccharide activates TBK1- and NF- $k B$-dependent immune response. a Quantitative RT-PCR analysis of $m C x c / 10$ and $m C x c / 2$ mRNA in knockout BMDMs (as indicated on the bottom) that were treated with $10 \mu \mathrm{M}$ of the Man $\beta 1-4 \mathrm{GlcNAc}$ disaccharide for $24 \mathrm{~h}$. $\mathbf{b}$ Quantitative RT$\mathrm{PCR}$ analysis of $m C x c 110$ and $m C x c / 2$ mRNA in BMDMs that were pretreated with the indicated inhibitors for $1 \mathrm{~h}$ and then treated with $10 \mu \mathrm{M}$ of the Man $\beta 1$ 4GIcNAc disaccharide for $24 \mathrm{~h}$. RUX, rituximab (JAK1/2 inhibitor), TPCA-1 and Dexamethasone are NF-kB inhibitors, Compound II and BX759 are TBK1 inhibitors. See Supplementary Fig. 6 for a diagram showing innate immune pathways tested here. Data are representative of at least three independent experiments. Error bars indicate SEM. Unpaired $t$-test

genes (e.g., $\mathrm{Ccl} 2, \mathrm{Ccl} 3, \mathrm{Cxcl} 2$, etc. Note: $\mathrm{Cxcl} 10$ is both an ISG and a chemokine) in response to Man $\beta 1-4$ GlcNAc (Fig. 6c).

Considering the similarities in immune profile between Man $\beta 1-4$ GlcNAc and chitosan, we next compared two additional disaccharides, N,N'-diacetylchitobiose (GlcNAc $\beta 1-4 G l c N A c)$ and chitobiose (GlcN $\beta 1-4 \mathrm{GlcN})$, as well as their respective polymers, chitin and chitosan. Neither disaccharide structure stimulated Cxcl10 or Cxcl2 expression in BMDM at up to $1000 \mu \mathrm{M}$, while Man $\beta 1-4 G l c N A c$ stimulated significant increased immune response at $100 \mu \mathrm{M}$. Chitosan, but not chitin, also stimulated robust Cxcl10 expression in BMDMs at very low concentration $(0.1 \mu \mathrm{M})$. These data further support the unique structure and immune activity of Man $\beta 1-4$ GlcNAc in comparison to other disaccharides. It also raises the possibility that polymeric form of Manß1-4GlcNAc (e.g., similar to chitobiose versus chitosan) could have more potent immune activities.

Man $\beta 1-4 G l c N A c$ enhances antibody response in vivo. To further substantiate our findings, we stimulated BMDCs with Man $\beta 1-4$ GlcNAc and found increased secretion of multiple chemokines, including $\mathrm{Cxcl10}, \mathrm{Ccl} 2, \mathrm{Ccl} 3$ (Fig. 7a). We did not detect activation markers of BMDCs such as MHC-II, CD86,
CD80 after Man $\beta 1-4 G l c N A c$ stimulation (Supplementary Fig. 7A, B). We also stimulated wild-type splenocytes ex vivo with the disaccharide and did not observe direct activation of either $\mathrm{T}$ or $\mathrm{B}$ cells (Supplementary Fig. 7C). All glycans are chemically synthesized and confirmed by structural analysis (Supplementary Figs. 8-20). We next tested the activity of Man $\beta 1-4 G l c N A c$ in vivo. We first transferred mixed OT1 and OT2 splenocytes into wild-type mice, then immunized subcutaneously with either vehicle, OVA alone, OVA + MG (Man $\beta 1-4$ GlcNAc) or OVA + LPS on day 0,7 , and 14 . Seven days after the last immunization, we collected serum for antibody analysis and splenocytes for IFN $\gamma$ ELISPOT assay. We detected significantly higher OVAspecific IgG1 in OVA + MG-treated mice compared to those treated with OVA alone, suggesting that Man $\beta 1-4 \mathrm{GlcNAc}$ enhanced B cell-mediated antibody response in vivo (Fig. $7 \mathrm{~b}$ ). Man $\beta 1-4 G l c N A c$ did not significantly enhance $T$ cell response (Fig. 7b). Interestingly, we previously showed that TREX1-V235fs mice develop serologic autoimmunity with increased autoantibody production in the serum and enhanced immune gene expression in cells ${ }^{6}$. Thus, together, our in vitro and in vivo data suggest that Man $\beta 1-4 \mathrm{GlcNAc}$ activates a broad immune profile in DCs and macrophages that are mediated in part through STING 
a

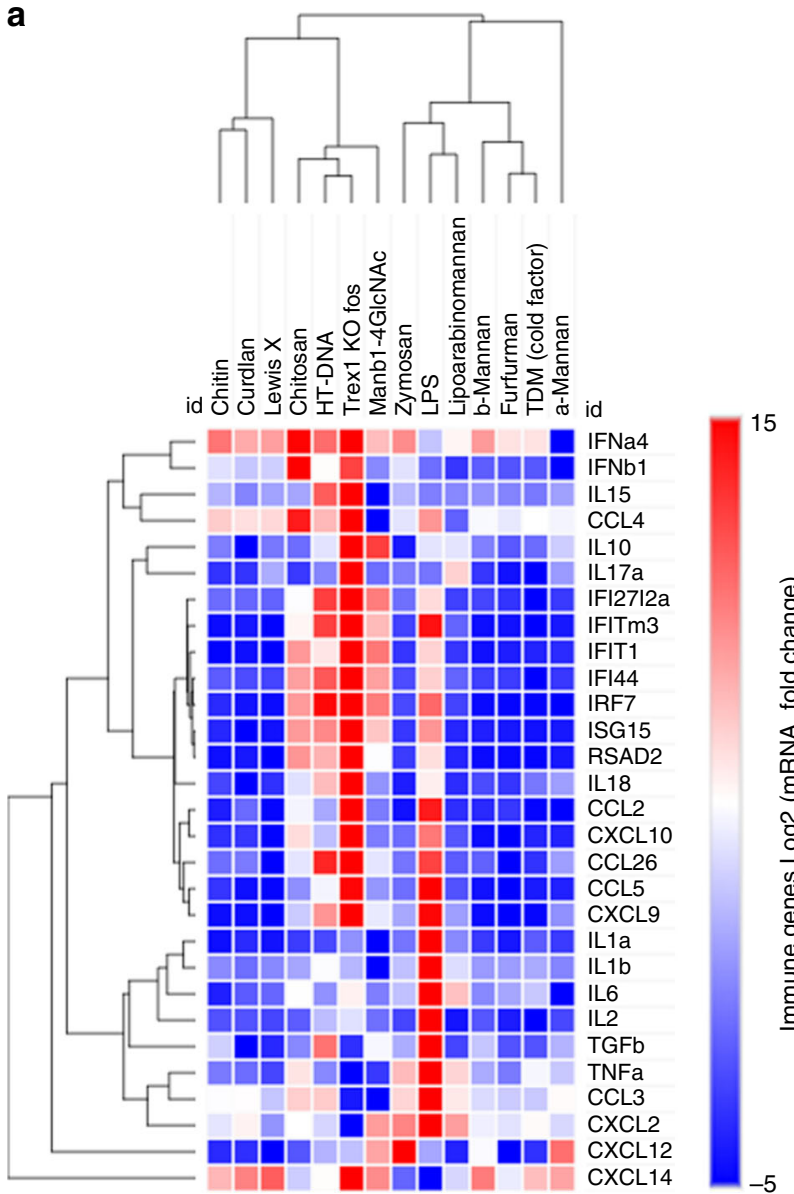

b

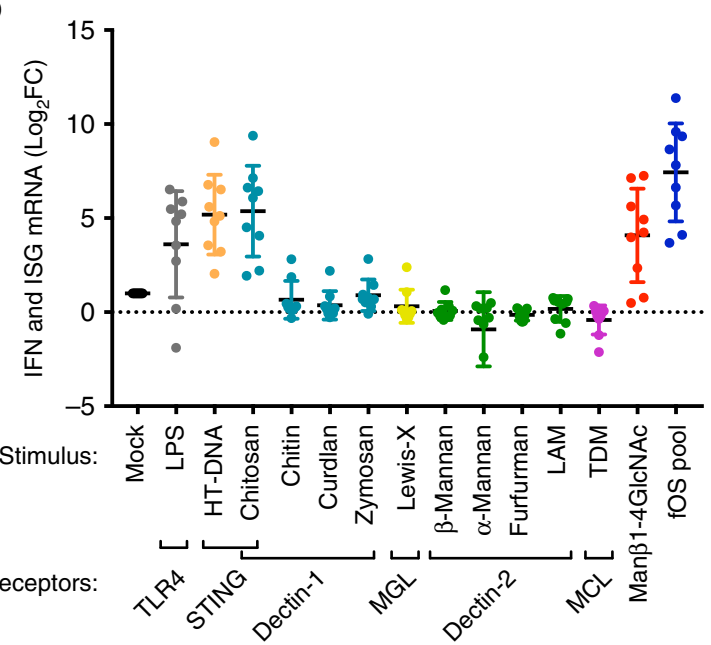

C

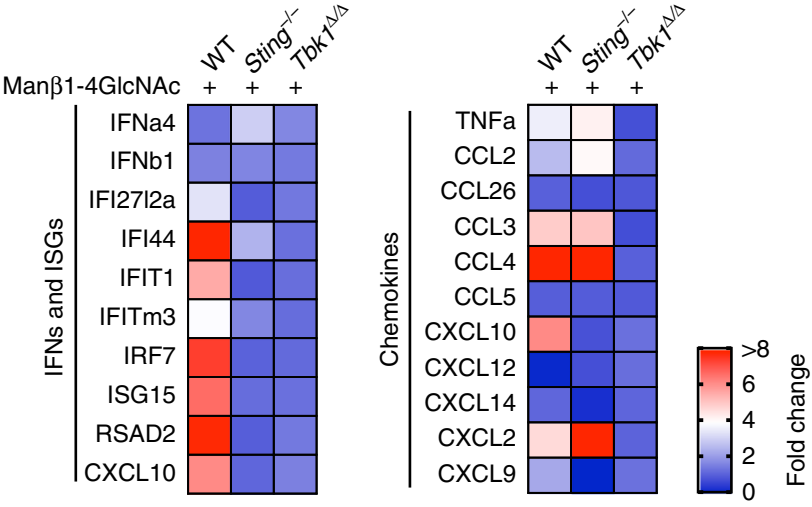

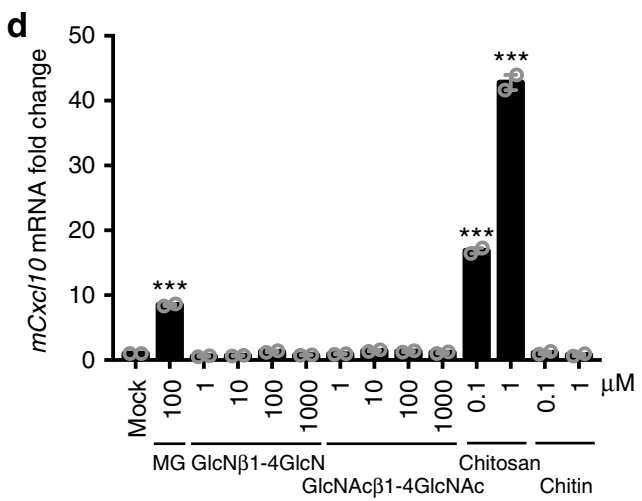

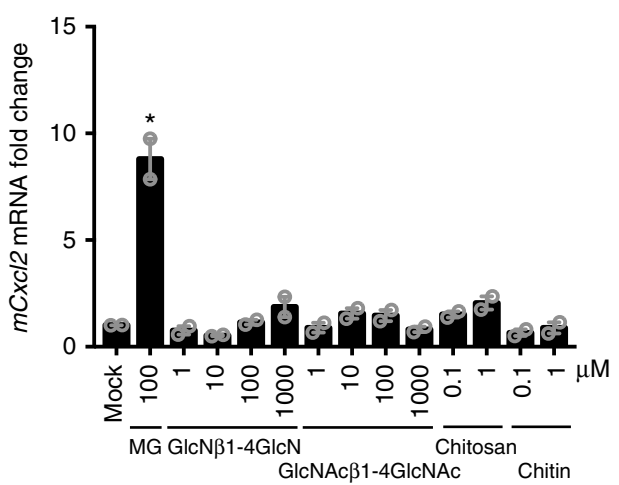

Fig. 6 The Man $\beta 1-4 G I c N A c$ disaccharide activates a broad immune gene signature that is similar to those acticated by DNA or chitosan. a Hierarchical heat map analysis of immune gene (as indicated on the right) expression in BMDMs treated with various ligands (as indicated on top) for $24 \mathrm{~h}$. mRNA expression of each gene was measured by GRT-PCR. b IFN and ISGs immune gene expression in BMDMs treated with various ligands (as indicated on bottom). Same gene expression data set as in a. Each dot represents one gene. c A heat map of immune gene expression in WT, Tbk $7^{\Delta / \Delta}$ and Sting ${ }^{-/-}$ BMDMs stimulated with Man $\beta 1-4 G I c N A c$ disaccharide for $24 \mathrm{~h}$. mRNA expression of each gene was measured by qRT-PCR. $\mathbf{d}$ Quantitative RT-PCR analysis of $m C x c / 10$ and $m C x c / 2$ mRNA in BMDMs that were treated with mock or indicated glycans (bottom) for 24 h. mRNA expression of each gene was measured by qRT-PCR. Data are from a representative set of at least two independent experiments. Error bars indicate SEM. Unpaired $t$-test

and other immune sensing pathway(s) that converge on TBK1, which lead to enhanced antibody response in vivo.

\section{Discussion}

Mammalian self-nucleic acids are well known for their causal association with autoimmune disease. Much less is known about whether and how mammalian self-glycans also activate immune responses associated with autoimmunity. Here, we identified a bioactive fOS, the Man $\beta 1-4 \mathrm{GlcNAc}$ disaccharide, that is produced by OST hydrolysis of LLOs in the ER lumen, processed by ENGase and mannosidases in the cytosol, and sensed in part by the cytosolic STING-TBK1-dependent innate immune pathway.

We found that the bioactivity of Man $\beta 1-4 \mathrm{GlcNAc}$ disaccharide requires both monosaccharides as well as the $\beta 1-4$ linkage, and this disaccharide is surprisingly active in comparison to other disaccharide we tested. The immune profile of Man $\beta 1-4 \mathrm{GlcNAc}$ is remarkably similar to that of chitosan, which also activates the 
a

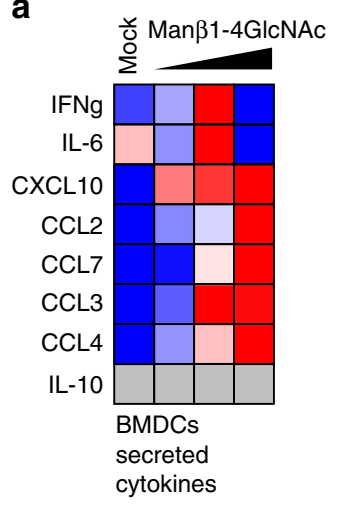

b

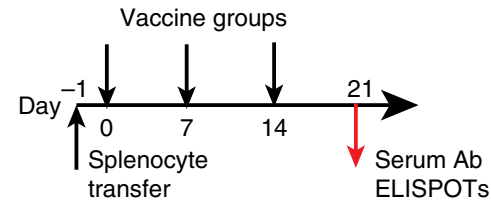

C

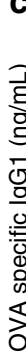

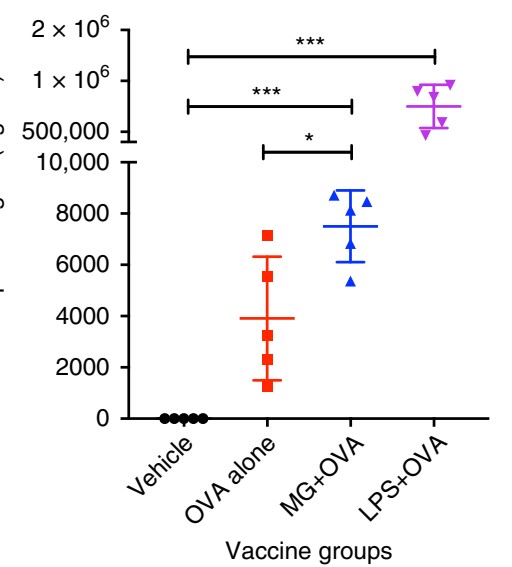

d

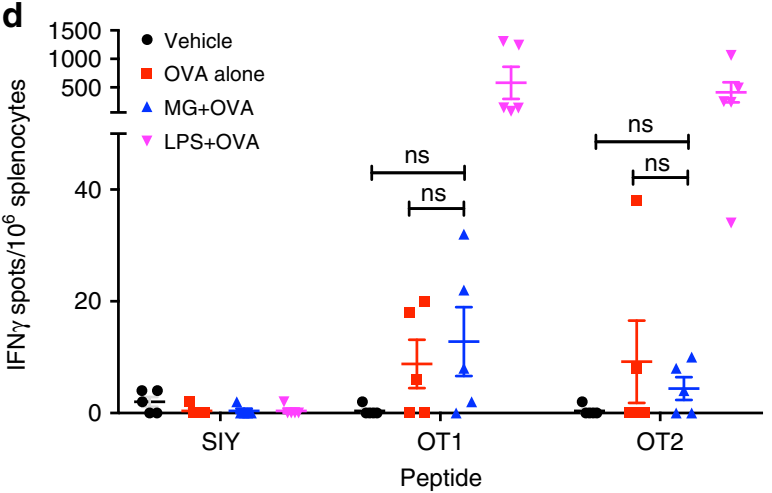

Fig. 7 The Man $\beta 1-4 G I c N A c$ disaccharide enhances antibody response in vivo. a Multiplex ELISA analysis of cytokines and chemokines secreted by BMDCs treated with mock or increasing amounts $(1,10$, and $100 \mu \mathrm{M})$ of the Man $\beta 1-4 \mathrm{GlcNAc}$ disaccharide for $24 \mathrm{~h}$. b A schematic diagram of Man $\beta 1-4 \mathrm{GlcNAc}$ mouse immunization experiment. See Method for more details. c OVA-specific IgG1 antibody titre by ELISA using serum at day 21 . Four vaccination groups are indicated on the bottom. MG, Man $11-4 G I c N A c . ~ N=5$. d IFN $\gamma$ ELISPOT assay using splenocytes at day 21. Five $\mu \mathrm{g} / \mathrm{ml}$ of OT1 OVA (257-264), OT2 OVA (323-339), or SIY (SIYRYYGL) peptide (negative control) were used to re-stimulate the antigen specific T cells. IFN- $\gamma$ production was determined 48 h later. Error bars indicate SEM. Unpaired t-test

STING-TBK1 pathway ${ }^{27}$. Structurally distinct chitosans also promote IFN or inflammasome responses ${ }^{28}$. Interestingly, chitosan is a polysaccharide of $\beta 1$-4-linked glucosamine $(\mathrm{GlcN})$, and we found that GlcN $\beta 1-4 \mathrm{GlcN}$ disaccharide alone does not have detectable immune activities even at high concentrations. Thus, given the impressive bioactivity of Man $\beta 1-4 \mathrm{GlcNAc}$, we expect that a polysaccharide containing repeats of Man $\beta 1$ 4 GlcNAc could potentially have very potent immunestimulating activities.

We further defined the immunogenicity of the Man $\beta 1-4 \mathrm{GlcNAc}$ disaccharide in vivo and in vitro. Using an immunization experiment with the model antigen OVA, we found that the disaccharide stimulated significantly increased antibody response but not $\mathrm{T}$ cell response, although the overall response is relatively weak. This is not surprising because: (1) The disaccharide is only one of several immunogenic glycans we identified; (2) Disaccharides are not expected to be highly immunogenic, and polysaccharides are. (3) The receptor for Man $\beta 1-4 \mathrm{GlcNAc}$ is likely intracellular. Nonetheless, the enhanced antibody response is consistent with our previous findings that TREX1-V235fs mice develop serologic autoimmunity ${ }^{6}$. We also defined the cell subsets affected by Man $\beta 1-4 G l c N A c$. Myeloid cells such as macrophages are directly activated by Man $\beta 1-4 G l c N A c$. DCs do respond to Man $\beta 1$ $4 \mathrm{GlcNAc}$ although to a less extent comparing to macrophages. Man $\beta 1-4 G l c N A c$ does not directly activate $\mathrm{T}$ and $\mathrm{B}$ cells when stimulated ex vivo. Thus, it is likely that Man $\beta 1-4$ GlcNAc primarily affects myeloid cells such as macrophages (through intracellular receptors) and induces expression of inflammatory cytokines and chemokines that promote a predominant B cellmediated antibody response. Future studies depleting these myeloid populations will help define their function in vivo.

Although the Man $\beta 1-4 G l c N A c$ disaccharide has not been found on pathogens as a PAMP, it has been associated with microbial metabolic activity for colonization or infection ${ }^{29,30}$. Bacterial pathogens digest mammalian $\mathrm{N}$-glycans on cells to facilitate infection. In doing so, many bacterial pathogens produce the Man $\beta 1-4 G l c N A c$ disaccharide and other fOSs, which are typically considered as by-products ${ }^{31}$. Therefore, it is possible that these mammalian fOSs produced during infection could function as danger-associated molecular patterns (DAMPs) that alert the host of the infection. In support of this notion, our previous work has demonstrated that fOSs are produced when cells are undergoing ER stress or infected with herpes simplex virus $1(\mathrm{HSV}-1)^{32}$.

Defects in cellular glycan processing enzymes can lead to chronic immune disorders. $\alpha$-mannosidase-II deficiency leads to production of $\mathrm{N}$-glycans that bear immune-stimulatory mannosedependent ligands that promote autoimmune diseases similar to lupus $^{3}$. Deficiency of $\beta$-mannosidase in humans and mice cause a chronic disease called $\beta$-mannosidosis, which causes accumulation of the Man $\beta 1-4 \mathrm{GlcNAc}$ disaccharide in multiple diseaseaffected tissues ${ }^{33,34}$ and neuropathological characteristics that resemble inflammation ${ }^{35,36}$. We previously showed that Trex1deficiency or $f s$ mutations dysregulate the OST complex leading to production of immunogenic high-mannose $\mathrm{fOS}^{5,6}$. Our data here further show that multiple bioactive fOS species are produced when OST is dysregualted, potentially each with distinct immune profile. Thus, our data reveal an exciting possibility for distinct mammalian fOSs, such as Man $\beta 1-4 G l c N A c$ defined here, to play a role in autoimmune disease pathogenesis. Lastly, our inhibitor studies targeting the biogenesis or immune sensing pathways of Man $\beta 1-4 \mathrm{GlcNAc}$ demonstrated several avenues of therapeutics for treating TREX1-fs RVCL, $\beta$-mannosidosis, and potentially other chronic autoimmune diseases.

\section{Methods}

Cells, antibodies, and reagents. MEFs, RAW264.7, BMDM, and BMDC were maintained in Dulbecco's modified Eagle's medium (DMEM) with $10 \%(\mathrm{v} / \mathrm{v}$ ) heatinactivated fetal bovine serum (FBS), with $2 \mathrm{mM}$ L-glutamine, $10 \mathrm{mM}$ HEPES, and $1 \mathrm{mM}$ sodium pyruvate (complete DMEM) with the addition of $100 \mathrm{U} / \mathrm{ml}$ 
penicillin, $100 \mathrm{mg} / \mathrm{ml}$ streptomycin except MEFs and cultured at $37^{\circ} \mathrm{C}$ with $5 \%$ $\mathrm{CO}_{2}$. MEFs, BMDM, and BMDCs were generated from WT C57BL/6 mice ${ }^{37}$. RAW264.7 cells were obtained from ATCC. Antibodies used in this study include anti-ubiquitin (rabbit, 1:1000 dilution, P4D1, Cell Signaling Technology), antiTubulin (mouse, 1:20,000 dilution, B-5-1-2, Sigma-Aldrich), anti-LC3 (rabbit, 1:1000 dilution,ab48394, Abcam), anti-STING (rabbit, 1:500 dilution, D2P2F, Cell Signaling), anti-GAPDH (rabbit, 1:1000 dilution, sc-25778, Santa Cruz), anti-Rab5 (rabbit, 1:1000 dilution,ab109534, Abcam), and anti-HMGB1 (rabbit; 1:2,000 dilution;ab18256; Abcam). The inhibitors used in this study are ACM (1 uM, Santa Cruz), Z-VAD-fmk (30 uM, BD), Q-VD-OPh (50 uM, BD), CSN (100 uM, Sigma-Aldrich), Kif (100 uM, Sigma-Aldrich), ES1 (10 uM, Sigma-Aldrich), CHX (10 ug/ml, Sigma-Aldrich), MG132 (1 uM, Sigma-Aldrich), Swain (10 uM, Tocris), Clq (10 uM, Sigma-Aldrich), Compound II (1 uM, UTSW), BX759 (1 uM, Invivogen), Ruxolitinib (1 uM, Invivogen), Dexamethasone (100 nM, Invivogen), and TPCA1 (1 uM, Sigma-Aldrich). The ligands used to stimulate macrophages are GalGlcNAc (Sigma-Aldrich), Mannose (Sigma-Aldrich), GlcNAc

(Sigma-Aldrich), Mana1- $\mathrm{CH}_{3}$ (Sigma-Aldrich), Man $\beta 1-\mathrm{CH}_{3}$ (Santa Cruz), LPS (100 ng/ml, Invivogen), htDNA (1 ug, Sigma-Aldrich), Chitosan (10 ug/ml, Invivogen), Chitin (10 ug/ml, Sigma-Aldrich), Curdlan (10 ug/ml, Invivogen), Zymosan (10 ug/ml, Invivogen), $\mathrm{Le}^{\mathrm{X}}(10 \mathrm{ug} / \mathrm{ml}$,Sigma-Aldrich), $\beta$-Mannan $(10 \mathrm{ug} / \mathrm{ml}$, Megazyme), $\alpha$-Mannan (10 ug/ml, Sigma-Aldrich), Furfurman (10 ug/ml, Invivogen), Lipoarabinomannan $(1 \mathrm{ug} / \mathrm{ml}$, Invivogen), and Cord factor $(1 \mathrm{ug} / \mathrm{ml}$, Invivogen). The alpha-mannosidase used in Fig. $1 \mathrm{~b}$ is alpha( $(1-2,3,6)$ mannosidase from Jack bean (Prozyme, catalog number GKX-5010). It can remove all alpha-mannose from high-mannose-type glycans (unless they are capped by glucose). All uncropped western blot scans are in Source Data.

Glycan analysis. Fluorophore-assisted carbohydrate electrophoresis (FACE) analysis was done as follows (also described in ref. ${ }^{5}$ ). Briefly, MEFs were plated at 75-80\% confluency and transfected (RNAiMAX, Thermo Fisher) with the ENGase siRNA (Sigma-Aldrich) or treated with inhibitors for $24 \mathrm{~h}$ and disrupted with methanol the next day. The methanol disrupted cells or the lyophilized media were subject to a three-phase (aqueous, interface, and organic) extraction, which yields an aqueous fraction containing neutral fOS (desalted by ion exchange chromatography) and an interface fractions, which was extracted with chloroform:methanol: water $(10: 10: 3)$ to isolate total proteins that was used to normalize the loading of labeled fOS to gels, immunoblotting and for the isolation of $\mathrm{N}$-linked glycans by PNGase F digestion (New England Biolabs). Isolated glycans (fOS and digested Nglycans) were conjugated with 7-amino-1,3-naphthalenedisulfonic acid (ANDS, AnaSpec) and subjected to reductive amination with $\mathrm{NaBH}_{3} \mathrm{CN}$ (Sigma-Aldrich) for $24 \mathrm{~h}$ at $37^{\circ} \mathrm{C}$. Labeled fOS and digested N-glycans were resolved on an oligosaccharide profiling gel, with $10 \mathrm{pmol}$ of glucose oligomers (ranging from four to seven glucosyl residues) and $100 \mathrm{pmol}$ of $\mathrm{Man}_{9} \mathrm{GlcNAc}_{2}$ (Sigma-Aldrich), $\mathrm{Man}_{5^{-}}$ $\mathrm{GlcNAc}_{2}$ (Sigma-Aldrich), $\mathrm{Man}_{2} \mathrm{GlcNAc}$ and ManGlcNAc as standards. Gels were visualized using a UVP Chemidoc-ItII scanner and quantified with VisionWorks software.

RNA isolation, RNA sequencing, and quantitative RT-PCR. Approximately $0.5 \times 10^{6}$ RAW264.7 cells or BMDM were seeded in a 12-well plate and stimulated the next day with the indicated ligands for $24 \mathrm{~h}$ by addition to the media or permeabilization as describe in ref. ${ }^{5}$ and ref. ${ }^{25}$, respectively. Total RNA was subsequently isolated with TRI reagent (Sigma-Aldrich) as indicated by the manufacturer and CDNA was synthesized with iScript cDNA synthesis kit (BioRad) and analyzed using a Bio-Rad CFX qRT-PCR. PCR array of immune gene groups was performed using PrimePCR Array plates using iTaq Universal SYBR Green Supermix (Bio-Rad). RNA-Seq was performed as previously described in ref. ${ }^{37}$. Pathway analysis was done using the Ingenuity Pathway Analysis software (Qiagen). Primers used in this study are in Supplementary Table 1.

Gel-filtration chromatography and mannosidase digestion. A $0.5 \times 20 \mathrm{~cm}$ column was packaged with $6 \mathrm{ml}$ of the BioGel P4 resin (Bio-Rad) and conditioned with a $25 \mathrm{mM} \mathrm{NH}_{4} \mathrm{CH}_{3} \mathrm{COO}$ (Sigma-Aldrich) buffer. Ten nanomoles of the total fOS were loaded into the column and 24 fractions ( $500 \mathrm{ul}$ per fraction) were collected. Sample were dried in vacuum and later resuspended in water and desalted by ion exchange chromatography. Ten percent of each fraction was collected for FACE analysis, and the remaining $90 \%$ was divided in half and used for macrophage stimulation in biological duplicates. For the mannosidase digestion, $10 \mathrm{nmol}$ of fOS or the synthetic ManGlcNAc disaccharide were treated with $40 \mathrm{U}$ of a1-6 mannosidase (New England Biolabs) and $32 \mathrm{U}$ of $\alpha 1-2,3$ mannosidase (New England Biolabs). Samples were then mixed with 3 volumes of cold ethanol and centrifuged at $20,000 \times \mathrm{g}$ for $20 \mathrm{~min}$ at $4^{\circ} \mathrm{C}$. The supernatant was dried in vacuum and later resuspended in water and desalted by ion exchange chromatography. Ten percent of the digested product was collected for FACE analysis and the remaining $90 \%$ was divided in half and used for macrophage stimulation in biological duplicates.

Structural analysis of free oligosaccharides. Free oligosaccharides in wild-type and Trex $1^{-1-}$ cells were prepared as follows (also described in ref. ${ }^{11}$ ). Briefly, 0.32 $\mathrm{g}$ of wild-type cells or $0.14 \mathrm{~g}$ of Trex $1^{-/}$cells were resuspended with $800 \mathrm{ul}$ of homogenization buffer (10 mM Hepes/NaOH buffer (pH 7.4) containing $5 \mathrm{mM}$ dithiothreitol, $250 \mathrm{mM}$ mannitol, $1 \mathrm{mM}$ EDTA, $1 \mathrm{x}$ complete protease inhibitor cocktail (EDTA-free; Roche Applied Science), and $1 \mathrm{mM}$ of Pefabloc (Roche Applied Science)). After the cells were homogenized in a Potter-Elvehjem homogenizer, the supernatant of $100,000 \times g$ centrifuged samples was obtained. The supernatant fractions were mixed with 3 volumes of cold ethanol, followed by centrifugation at $17,000 \times g$ for $20 \mathrm{~min}$ at $4{ }^{\circ} \mathrm{C}$. The supernatants were dried, and desalted using a PD-10 column (GE Healthcare). The free oligosaccaharide fraction thus obtained were subjected to fluorescence-labeling with 2-aminopyridine (PA). Detailed methods for PA-labeling, as well as removal of excess reagents were described previously ${ }^{38}$. Separation of PA-labeled free oligosaccaharides were carried out first by size-fractionation using a Shodex NH2P-50 3E column $(3.0 \times 250$ $\mathrm{mm}$; Shodex, Tokyo, Japan) as described previously ${ }^{39}$. Each PA-labeled glycans were further separated by a dual-gradient HPLC as described previously ${ }^{40}$. Structures of each PA-glycan isolated were confirmed by a co-elution of standard PA-glycans as prepared previously ${ }^{11}$.

Mouse immunization study. C57BL/6 mice were transferred with mixed splenocytes $\left(2 \times 10^{6}\right.$ for each) from OT1 and OT2 transgenic mice on day 1 , and then immunized subcutaneously with $100 \mu \mathrm{g}$ OVA together with/without $100 \mu \mathrm{g}$ Man $\beta 1-4$ GlcNAc or $20 \mu \mathrm{g}$ LPS on day 0,7 , and 14 . Seven days after the last immunization, serum of treated mice was collected for antibody detection with ELISA, and splenocytes were isolated for IFN $\gamma$ ELISPOT assay. Serum anti-OVA IgG1 was measured using an ELISA kit per manufacturer's protocol (Cayman \#500830). Spleens from treated mice were processed into single cell suspensions and resuspended in RPMI 1640 medium supplemented with $10 \%$ fetal bovine serum, $2 \mathrm{mmol} / \mathrm{l} \mathrm{L}$-glutamine, $100 \mathrm{U} / \mathrm{ml}$ penicillin, and $100 \mu \mathrm{g} / \mathrm{ml}$ streptomycin. $5 \times 10^{5}$ splenocytes were used for the IFN $\gamma$ ELISPOT assay, $5 \mu \mathrm{g} / \mathrm{ml}$ of OVA (257264), OVA (323-339), or SIY (SIYRYYGL) peptide were used to re-stimulate the antigen specific T cells. IFN- $\gamma$ production was determined $48 \mathrm{~h}$ after of incubation with an IFN- $\gamma$ ELISPOT assay kit according to the manufacturer's protocol (BD Biosciences). The visualized spots were enumerated with the CTL-ImmunoSpot ${ }^{\oplus}$ S6 Analyzer (Cellular Technology Limited)

All mice were housed in pathogen-free barrier facility in UT Southwestern Medical Center. Both male and female 6-8 week old mice were used. All mice were on C57BL/6 background. Five mice per group were used in each repeat of the experiment. All mouse experiments were approved by ICUAC in UT Southwestern Medical Center.

Glycan synthesis. See Supplementary Methods.

Reporting summary. Further information on research design is available in the Nature Research Reporting Summary linked to this article.

\section{Data availability}

All raw data, original gel images, processed RNA-seq data and pathway analysis are included in the Source Data file. Original RNA-seq data are deposited at NCBI gene expression omnibus (GEO, accession number GSE129677).

Received: 24 April 2018 Accepted: 25 April 2019

Published online: 30 May 2019

\section{References}

1. Sancho, D. \& Reis e Sousa, C. Signaling by myeloid C-type lectin receptors in immunity and homeostasis. Annu. Rev. Immunol. 30, 491-529 (2012).

2. Rabinovich, G. A., van Kooyk, Y. \& Cobb, B. A. Glycobiology of immune responses. Ann. N. Y. Acad. Sci. 1253, 1-15 (2012).

3. Green, R. S. et al. Mammalian N-glycan branching protects against innate immune self-recognition and inflammation in autoimmune disease pathogenesis. Immunity 27, 308-320 (2007).

4. Yan, N. Immune diseases associated with TREX1 and STING dysfunction. J. Interferon Cytokine Res. 37, 198-206 (2017).

5. Hasan, M. et al. Cytosolic nuclease TREX1 regulates oligosaccharyltransferase activity independent of nuclease activity to suppress immune Activation. Immunity 43, 463-474 (2015).

6. Sakai, T. et al. DNase-active TREX1 frame-shift mutants induce serologic autoimmunity in mice. J. Autoimmun. 81, 13-23 (2017).

7. Gall, A. et al. Autoimmunity initiates in nonhematopoietic cells and progresses via lymphocytes in an interferon-dependent autoimmune disease. Immunity 36, 120-131 (2012).

8. Grieves, J. L. et al. Exonuclease TREX1 degrades double-stranded DNA to prevent spontaneous lupus-like inflammatory disease. Proc. Natl Acad. Sci. USA 112, 5117-5122 (2015). 
9. Lee-Kirsch, M. A. et al. Mutations in the gene encoding the 3'-5' DNA exonuclease TREX1 are associated with systemic lupus erythematosus. Nat. Genet. 39, 1065-1067 (2007).

10. Richards, A. et al. C-terminal truncations in human $3^{\prime}-5^{\prime}$ DNA exonuclease TREX1 cause autosomal dominant retinal vasculopathy with cerebral leukodystrophy. Nat. Genet. 39, 1068-1070 (2007).

11. Seino, J. et al. Basal autophagy is required for the efficient catabolism of sialyloligosaccharides. J. Biol. Chem. 288, 26898-26907 (2013).

12. Harada, Y. et al. Eukaryotic oligosaccharyltransferase generates free oligosaccharides during N-glycosylation. J. Biol. Chem. 288, 32673-32684 (2013).

13. Harada, Y., Hirayama, H. \& Suzuki, T. Generation and degradation of free asparagine-linked glycans. Cell. Mol. life Sci. 72, 2509-2533 (2015).

14. Bennett, D. C. et al. High-throughput screening identifies aclacinomycin as a radiosensitizer of EGFR-mutant non-small cell lung cancer. Transl. Oncol. 6, 382-391 (2013).

15. Kessler, B., Spooner, E., Korbel, G. A., Ploegh, H. L. \& Misaghi, S. z-VAD-fmk inhibits peptide:N-glycanase and may result in ER stress. Cell Death Differ. 13, 163 (2005)

16. Haga, Y., Totani, K., Ito, Y. \& Suzuki, T. Establishment of a real-time analytical method for free oligosaccharide transport from the ER to the cytosol. Glycobiology 19, 987-994 (2009).

17. Hebert, D. N., Lamriben, L., Powers, E. T. \& Kelly, J. W. The intrinsic and extrinsic effects of N-linked glycans on glycoproteostasis. Nat. Chem. Biol. 10, 902-910 (2014).

18. Moore, S. Transport of free polymannose-type oligosaccharides from the endoplasmic reticulum into the cytosol is inhibited by mannosides and requires a thapsigargin-sensitive calcium store. Glycobiology 8, 373-381 (1998).

19. Iannotti, M. J., Figard, L., Sokac, A. M. \& Sifers, R. N. A Golgi-localized mannosidase (MAN1B1) plays a non-enzymatic gatekeeper role in protein biosynthetic quality control. J. Biol. Chem. 289, 11844-11858 (2014).

20. Moore, S. Oligosaccharide transport: pumping waste from the ER into lysosomes. Trends Cell Biol. 9, 441-446 (1999).

21. Winchester, B. Lysosomal metabolism of glycoproteins. Glycobiology 15, 1R-15R (2005).

22. Suzuki, T. Catabolism of N-glycoproteins in mammalian cells: molecular mechanisms and genetic disorders related to the processes. Mol. Asp. Med. 51, 89-103 (2016).

23. Harada, Y., Masahara-Negishi, Y. \& Suzuki, T. Cytosolic-free oligosaccharides are predominantly generated by the degradation of dolichol-linked oligosaccharides in mammalian cells. Glycobiology 25, 1196-1205 (2015).

24. Tulsiani, D. R. \& Touster, O. Substrate specificities of rat kidney lysosomal and cytosolic alpha-D-mannosidases and effects of swainsonine suggest a role of the cytosolic enzyme in glycoprotein catabolism. J. Biol. Chem. 262, 6506-6514 (1987).

25. Orzalli, M. H. et al. cGAS-mediated stabilization of IFI16 promotes innate signaling during herpes simplex virus infection. Proc. Natl Acad. Sci. USA 10.1073/pnas.1424637112 (2015).

26. Kapellos, T. S. et al. A novel real time imaging platform to quantify macrophage phagocytosis. Biochem. Pharmacol. 116, 107-119 (2016).

27. Carroll, E. C. et al. The vaccine adjuvant chitosan promotes cellular immunity via DNA Sensor cGAS-STING-dependent induction of type I interferons. Immunity 44, 597-608 (2016).

28. Fong, D. et al. Lysosomal rupture induced by structurally distinct chitosans either promotes a type 1 IFN response or activates the inflammasome in macrophages. Biomaterials 129, 127-138 (2017).

29. Curtis, M. M. et al. The gut commensal bacteroides thetaiotaomicron exacerbates enteric infection through modification of the metabolic landscape. Cell Host Microbe 16, 759-769 (2014).

30. Cuskin, F. et al. Human gut Bacteroidetes can utilize yeast mannan through a selfish mechanism. Nature 517, 165-169 (2015).

31. Robb, M. et al. Molecular characterization of N-glycan degradation and transport in Streptococcus pneumoniae and its contribution to virulence. PLOS Pathogens 13, 1-33 (2017).

32. Gao, N. et al. Mannose-6-phosphate regulates destruction of lipid-linked oligosaccharides. Mol. Biol. Cell 22, 2994-3009 (2011).

33. Zhu, M. et al. $\beta$-Mannosidosis mice: a model for the human lysosomal storage disease. Hum. Mol. Genet. 15, 493-500 (2006).
34. van Pelt, J. et al. Accumulation of mannosyl-beta(1----4)-N-acetylglucosamine in fibroblasts and leukocytes of patients with a deficiency of betamannosidase. Clin. Chim. acta; Int. J. Clin. Chem. 187, 55-60 (1990).

35. Riise Stensland, H. M. F. et al. Identification of two novel beta-mannosidosisassociated sequence variants: biochemical analysis of beta-mannosidase (MANBA) missense mutations. Mol. Genet. Metab. 94, 476-480 (2008).

36. Zhu, M. et al. Beta-mannosidosis mice: a model for the human lysosomal storage disease. Hum. Mol. Genet. 15, 493-500 (2006).

37. Hasan, M. et al. Trex1 regulates lysosomal biogenesis and interferonindependent activation of antiviral genes. Nat. Immunol. 14, 61-71 (2012).

38. Hirayama, H., Seino, J., Kitajima, T., Jigami, Y. \& Suzuki, T. Free oligosaccharides to monitor glycoprotein endoplasmic reticulum-associated degradation in Saccharomyces cerevisiae. J. Biol. Chem. 285, 12390-12404 (2010).

39. Hossain, T., Hirayama, H., Harada, Y. \& Suzuki, T. Lack of the evidence for the enzymatic catabolism of Man1GlcNAc2 in Saccharomyces cerevisiae. Biosci., Biotechnol., Biochem. 80, 1-6 (2015).

40. Suzuki, T. et al. Dual-gradient high-performance liquid chromatography for identification of cytosolic high-mannose-type free glycans. Anal. Biochem. 381, 224-232 (2008).

\section{Acknowledgements}

We would like to thank Dr. Jennifer Kohler and members of the Yan lab for valuable discussions. This work was supported by the Lupus Research Alliance (N.Y.), the Clark family CRV Research Foundation (N.Y.), the NIH (AR067135 to N.Y., GM038545 to M.A.L.), the Welch Foundation (I-1831 to N.Y.) and NSF-GRFP fellowship (C.F.).

\section{Author contribution}

C.F. designed and performed most of the experiments and analyzed data. N.D. helped with in vitro stimulation and some in vivo experiments. K.S., N.I., and I.M. synthesized glycans used in this study. J.S. and T.S. performed structural analysis of fOSs. Z.L. and Y.-X.F. performed in vivo mouse experiments. M.A.L. provided expertise in FACE analysis and advice on experimental design. C.F. and N.Y. conceived the study, designed experiments, analyzed data, and wrote the manuscript with input from all co-authors.

\section{Additional information}

Supplementary Information accompanies this paper at https://doi.org/10.1038/s41467 019-10319-5.

Competing interests: The authors declare no competing interests.

Reprints and permission information is available online at http://npg.nature.com/ reprintsandpermissions/

Journal peer review information: Nature Communications thanks the anonymous reviewer(s) for their contribution to the peer review of this work.

Publisher's note: Springer Nature remains neutral with regard to jurisdictional claims in published maps and institutional affiliations.

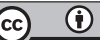

Open Access This article is licensed under a Creative Commons Attribution 4.0 International License, which permits use, sharing, adaptation, distribution and reproduction in any medium or format, as long as you give appropriate credit to the original author(s) and the source, provide a link to the Creative Commons license, and indicate if changes were made. The images or other third party material in this article are included in the article's Creative Commons license, unles indicated otherwise in a credit line to the material. If material is not included in the article's Creative Commons license and your intended use is not permitted by statutory regulation or exceeds the permitted use, you will need to obtain permission directly from the copyright holder. To view a copy of this license, visit http://creativecommons.org/ licenses/by/4.0/.

(c) The Author(s) 2019 